\title{
1 Endogenization from diverse viral ancestors is common and widespread in parasitoid wasps
}

2 Gaelen R. Burke ${ }^{1 *}$, Heather M. Hines ${ }^{2}$, Barbara J. Sharanowski ${ }^{3}$

3

\section{Affiliations:}

$5{ }^{1}$ Department of Entomology, University of Georgia, Athens, GA 30606, USA

$6{ }^{2}$ Department of Biology and Department of Entomology, Pennsylvania State University, University Park,

7 PA 16802 USA

$8{ }^{3}$ Department of Biology, University of Central Florida, Orlando, FL 32816, USA

9 *Author for Correspondence: Gaelen R. Burke, Department of Entomology, University of Georgia,

10 Athens, GA, USA, grburke@uga.edu

\section{Abstract}

13 The Ichneumonoidea (Ichneumonidae and Braconidae) is an incredibly diverse superfamily of parasitoid

14 wasps that includes species that produce virus-like entities in their reproductive tracts to promote

15 successful parasitism of host insects. Research on these entities has traditionally focused upon two viral

16 genera Bracovirus (in Braconidae) and Ichnovirus (in Ichneumonidae). These viruses are produced using

17 genes known collectively as endogenous viral elements (EVEs) that represent historical, now heritable

18 viral integration events in wasp genomes. Here, new genome sequence assemblies for eleven species and

19 six publicly available genomes from the Ichneumonoidea were screened with the goal of identifying novel

20 EVEs and characterizing the breadth of species in lineages with known EVEs. Exhaustive similarity

21 searches combined with the identification of ancient core genes revealed sequences from both known and

22 novel EVEs. Two species harbored novel, independently derived EVEs related to a divergent large 
23 double-stranded DNA (dsDNA) virus that manipulates behavior in other hymenopteran species. While

24 bracovirus or ichnovirus EVEs were identified as expected in three species, the absence of ichnoviruses in

25 several species suggests that they are independently derived and present in two younger, less widespread

26 lineages than previously thought. Overall, this study presents a novel bioinformatic approach for EVE

27 discovery in genomes and shows that three divergent virus families (nudiviruses, the ancestors of

28 ichnoviruses, and LbFV-like viruses) are recurrently acquired as EVEs in parasitoid wasps. Virus

29 acquisition in the parasitoid wasps is a common process that has occurred in many more than two lineages

30 from a diverse range of arthropod-infecting dsDNA viruses.

\section{Key words}

33 Ichneumonoidea, virus, endogenous virus element (EVE), polydnaviruses (PDVs), parasitoid wasp

34 genomes

\section{Significance}

37 Parasitoid wasps are an extremely diverse group of animals that are known to harbor Endogenous Virus

38 Elements (EVEs) that produce virions or virus-like particles of key importance in wasps' parasitism

39 success. However, the prevalence and diversity of independently acquired EVEs in parasitoid wasp

40 lineages has remained largely uncharacterized on a widespread scale. This study represents an important

41 first step and hints at the massive, untapped diversity of EVEs in parasitoid wasps via the identification of

42 several novel virus co-option events from diverse groups of double-stranded DNA virus pathogens. 


\section{Introduction}

45 Although viruses have long been viewed as pathogenic organisms, there is now ample evidence

46 that viruses can confer important benefits to their hosts and have played a major role in the evolution of

47 life on earth (Goic \& Saleh 2012; Villarreal \& Witzany 2010; Schmitt \& Breinig 2002; Ryabov et al.

48 2009; Rossignol et al. 1985; Barton et al. 2007; Brown et al. 2006; Malmstrom et al. 2005; Moran et al.

49 2005; Strand \& Burke 2020; Dunlap et al. 2006). Further, in most sequenced eukaryotic genomes there is

50 evidence of viral gene "footprints" (Feschotte \& Gilbert 2012), suggesting viral endogenization is

51 common and could play an important role in genome and organismal evolution. Understanding how

52 beneficial viral associations evolve is essential for a holistic view on the evolution of eukaryotic

53 organisms (Roossinck 2011; Villarreal 2015).

54 Perhaps some of the most complex examples of viral endogenization occur in parasitic wasps

55 belonging to the exceptionally diverse superfamily Ichneumonoidea (Braconidae + Ichneumonidae) with

56 more than 44,000 described species (Yu et al. 2012). As parasitoids, these wasps lay their eggs in or on

57 other insect "hosts", where their progeny feed and complete the immature stages of development,

58 resulting in the death of the host. Conservative estimates suggest that one in ten animals is a parasitoid

59 wasp (Askew 1971) and more recent estimates exceed these already astonishing numbers (Forbes et al.

60 2018; Jones et al. 2009; Rodriguez et al. 2013). Among parasitoid wasps, Ichneumonoidea are particularly

61 diverse, comprising $\sim 28 \%$ of all Hymenoptera, $\sim 3 \%$ of all terrestrial, multicellular life (Chapman 2009;

62 Yu et al. 2012) and parasitizing a broad range of insects and other arthropods. To facilitate host invasion,

63 ichneumonoid wasps are known to employ novel viral associations in the form of Endogenous Viral

64 Elements (EVEs), in which elements of viral genomes become permanently integrated into the genomes

65 of wasps (Bezier et al. 2009; Burke, Simmonds, et al. 2018; Pichon et al. 2015; Volkoff et al. 2010;

66 Béliveau et al. 2015). EVEs produce virions or virus-like particles (VLPs) in ovaries of these wasps,

67 which are injected into hosts during parasitism. Based upon experimental studies in a number of 
68 representative species, it is thought that these viruses function in the promotion of successful parasitism

69 (Edson et al. 1981; Beckage et al. 1994; Rotheram \& Salt 1973; Salt 1965) and may contribute to the

70 immense diversity of these parasitic wasps. Viruses or VLPs function in the delivery of virulence

71 molecules such as DNA or proteins that suppress host immune defenses or alter host development and

72 behavior in ways that facilitate survival, growth and development of the larval parasitoid (Strand 2012;

73 Darboux et al. 2019; Lee et al. 2009; Reineke et al. 2006). Remarkably, many if not all viruses or VLPs

74 produced by wasps stem from pathogenic viral ancestors (Pichon et al. 2015; Bezier et al. 2009; Burke,

75 Simmonds, et al. 2018; Stasiak et al. 2005).

77 documented to occur within select but diverse clades within Ichneumonoidea. In Braconidae, they are

78 present in the microgastroid complex (sensu Sharanowski et al. 2011) comprising at least 6 subfamilies

79 with more than 3900 described species. In Ichneumonidae, PDVs have been discovered in two families:

80 Campopleginae and Banchinae, with more than 2,200 and 1,750 described species, respectively (Yu et al.

81 2012). Most large double-stranded DNA viruses have genes that can be divided into two categories: 1)

82 replication genes, which encode essential replication machinery and are conserved among genomes, and

83 2) virulence genes of diverse origins whose products interact with host defenses and are gained and lost

84 much more rapidly (Yutin et al. 2009; Kawato et al. 2018; Rohrmann 2011). PDVs have two components

85 that are dispersed within the genomes of wasps: replication genes and proviral segments (the regions of

86 the genome that are packaged into virions and contain virulence genes). The replication machinery for

87 these viruses is not packaged into virions, making PDVs replication-defective and thus reliant on the wasp

88 for replication (Strand \& Burke 2014; Burke et al. 2014; Bézier et al. 2009; Bézier et al. 2013; Volkoff et

89 al. 2010). The inheritance of permanently integrated PDVs is predicted to produce genetically unique, but

90 related EVEs in each wasp species within the three major clades of PDV-carrying wasps (Whitfield \&

91 Asgari 2003). 
93 unique origins. The family Polydnaviridae is divided into two genera: Bracovirus and Ichnovirus (Strand

94 \& Drezen 2012). The morphology of the polydnaviruses found in Ichneumonidae (ichnoviruses) and

95 Braconidae (bracoviruses) are vastly different (Stoltz \& Whitfield 1992), and genomic sequences of the

96 replication machinery show affinity to different classes of viruses (insect beta-nudiviruses and related

97 baculoviruses for bracoviruses; relatives of nucleocytoplasmic large DNA viruses (NCLDVs) for

98 ichnoviruses) (Béliveau et al. 2015; Bezier et al. 2009; Volkoff et al. 2010). In the Braconidae,

99 bracoviruses have been localized histologically in species across the monophyletic microgastroid complex

100 (Whitfield, 1997), suggesting a single PDV origin in this clade 100 Mya (Murphy et al. 2008). Ichneumonoidea. For example, in the ichneumonid Venturia canescens (Campopleginae), viral replication genes were co-opted from the insect alpha-nudiviruses (related but distinct from the PDV progenitors, the

104 beta-nudiviruses) and used to produce VLPs in wasp ovaries (Pichon et al. 2015). The $V$. canescens

105 genome lacks the genes required to make a capsid to house viral DNA in virions, preventing delivery of

106 virulence genes but allowing delivery of wasp-derived virulence proteins into hosts within VLPs

107 (Feddersen et al. 1986; Pichon et al. 2015). Through wasp genome sequencing, an independent

108 acquisition of viral genes from the alpha-nudiviruses was recently identified in Fopius arisanus

109 (Braconidae), the first recognized incidence of viral genome integration in the subfamily Opiinae (Burke,

110 Simmonds, et al. 2018). Other reports of reproductive gland associated viruses in the Ichneumonoidea

111 have been published ( $>35)$, but are limited to the identification of virions in wasp tissues and do not

112 include any genetic analyses (Suzuki \& Tanaka 2006; Lawrence 2005). Two very recent studies have

113 documented the presence of EVEs outside of the Ichneumonoidea in parasitoid species belonging to the

114 Figitidae and Chalcididae (Di Giovanni et al. 2020; Zhang et al. 2020). Recently discovered EVEs have 115 not been assigned to Polydnaviridae because thus far no VLPs produced package DNAs and because the 
116 family is polyphyletic and likely to be revised in the future. These data suggest that viral co-option events

117 may be more common in parasitoids than previously thought.

118 Thus far, genetic discovery of these EVEs has been sporadic. Comprehensive exploration of the

119 number of integration events and the rules governing their acquisition and function requires

120 improvements in genomic pipelines for viral identification. In this study, we seek to better understand the

121 diversity of viral origins in ichneumonoid wasps through developing a comparative genomic approach for

122 EVE discovery. Using new genome sequence datasets in combination with publicly available genome

123 assemblies from species belonging to Ichneumonoidea, this research has three objectives: 1) to develop a

124 method for the identification of endogenous virus elements derived from diverse large double-stranded

125 DNA viruses; 2) to examine the breadth of PDV incidence in lineages known to produce bracoviruses and

126 ichnoviruses; and 3) to identify novel EVEs likely to produce virions or VLPs in species in which they

127 have not been described previously. Screening of 17 genomes from parasitoids within the

128 Ichneumonoidea (including eleven new genome assemblies) identified both familiar and novel EVEs in a

129 number of species. These results challenge existing assumptions about the species distribution and origins

130 of ichnoviruses, and find a new family of double-stranded DNA viruses that are common EVE

131 progenitors. 


\section{Materials and methods}

133 Wasp species sampling. Sharanowski et al. (2020) recently generated genome sequence datasets from 11

134 species for the purpose of resolving the phylogenetic relationships among species in the Ichneumonoidea.

135 The sampling included seven species from Ichneumonidae and four species from Braconidae, all derived

136 from different subfamilies to maximally capture diversity (Table 1, Supplementary Table 1). All DNA

137 samples used for sequencing were derived from single adult females, except Odontocolon sp, which was

138 sequenced from a single adult male. Additionally, six publicly-available genomes from the

139 Ichneumonoidea (five braconid and one ichneumonid species) with known presence or absence of viral

140 associations served as controls for this study (Table 1, Burke, Walden, et al. 2018; Shi et al. 2019; Tvedte

141 et al. 2019; Geib et al. 2017; Leobold et al. 2018; Yin et al. 2018).

143 Genome assembly. Illumina sequence reads generated from genomic DNAs from 11 wasp species 144 (PE100) were screened with trimmomatic v.0.36, using the parameters "LEADING:3 TRAILING:3

145 SLIDINGWINDOW:4:15 MINLEN:36". Any read pairs with overlapping 3' ends were merged with pear

146 v.0.9.8 using default settings. Paired reads, merged reads, and unpaired single reads were used as input for 147 de novo assembly of contigs using SPAdes v.3.12.0 (Bankevich et al. 2012) with kmers of 21, 33, 55, 77

148 bp and default parameters.

150 Database construction and rapid homology searches for curation of assemblies and identification of

151 EVEs. A custom database was made to identify contigs that contain genes of viral origin and exclude

152 contaminant contigs (Medd et al. 2018). The database contained all protein sequences from the NCBI

153 refseq database (downloaded February 2019) from Hymenoptera, Lepidoptera, Diptera, Coleoptera,

154 bacteria, archaea, nematodes, and fungi, and viral protein sequences from the NCBI nr database

155 (downloaded February 2019). TaxonKit v.0.3.0 was used to generate lists of all NCBI taxonomy ID 
156 numbers for included groups of organisms (Shen \& Xiong 2019). The software csvtk v.0.15.0

157 (https://bioinf.shenwei.me/csvtk/) was used to obtain accession numbers from proteins derived from

158 species with included taxonomy IDs using the NCBI database prot.accession2taxid.gz downloaded in

159 February of 2019. Protein sequences from included species were then extracted from the refseq and $\mathrm{nr}$

160 databases and made into a database with diamond v.1.0 (Buchfink et al. 2015). Sequences from

161 hymenopteran genomes with known EVEs were excluded so that any genes with viral origin would have

162 hits to viral proteins and be assigned to the correct taxonomic lineage (virus rather than insect). Genes

163 from complete polydnavirus genomes (proviral genome segments) were also excluded from the database

164 because they do not contain viral replication genes and do contain many genes of eukaryotic origin. The

165 final database contained 117,461,186 protein sequences.

166 ORFs were identified from genomic contigs (generated as described below) or scaffolds using

167 emboss v.6.6.0 getorf with minimum size of 150bp yielding between 247,340 and 691,147 ORFs per

168 genome assembly (Rice et al. 2000). ORFs were searched against the database described above with

169 diamond with an e-value threshold of 0.01, retaining a single top hit. NCBI taxonomy IDs were included

170 in diamond output reports.

172 Removal of sequence contaminants and assessment of assemblies. Contigs smaller than 200bp in size

173 were removed from final assemblies. Blobtools v1.1 (Laetsch \& Blaxter 2017), was used to retain only

174 those contigs that were assigned to Arthropoda and Viruses or that had no hits. Assembly statistics were

175 evaluated using quast v.5.0.2 (Gurevich et al. 2013). The completeness of each set of genome sequence

176 contigs was analyzed by identifying the number of arthropod Benchmark Universal Single-Copy

177 Orthologs (BUSCOs) (Simão et al. 2015). BUSCO v.3.0.2 was run on the assembled contigs or genome

178 scaffolds for previously published genomes (“-m geno") to identify orthologs in the Insecta ortholog

179 database version 9, using Nasonia models for gene prediction. 

mapped to the contigs using bowtie2 v.2.3.4.1, and coverage calculated with samtools bedcov v.1.9

182 (Langmead \& Salzberg 2013; Li et al. 2009). A similar process was used to determine read coverage of 183 genome scaffolds in previously published genomes, except that sequence reads were downloaded from 184 the NCBI Sequence Read Archive (SRA) when available and processed using trimmomatic and pear as 185 described above.

187 Identification of genes of viral origin in wasp genomes. Identification of virus-derived genes in wasp 188 genomes was done using several approaches. All eleven new and previously published genome 189 assemblies were searched without any a priori expectation for the presence of virus-derived genes by: 1) 190 exhaustively screening all ORFs from genome assemblies for viral hits against a curated database; and 2) 191 searching all ORFs for matches to ancient core genes found in large double-stranded DNA virus groups 192 that are known to infect insects (see below). These methods were expected to non-exhaustively discover 193 the presence of virus-derived genes to narrow down the list of species for which more detailed 194 identification and annotation should be performed.

195 i. Exhaustive screening of ORFs for viral hits. The first approach used was modified from Medd et al.

196 2018, and used exhaustive similarity searches of all possible Open Reading Frames (ORFs) (of a

197 minimum size) against a curated database to identify sequences with similarity to viral proteins. Despite 198 the fragmented state of the newly added genome assemblies, it was reasoned that the majority of genes of 199 viral origin and architecture would be intact (not be broken into pieces across contigs) because N50 200 values were equal to or greater than the expected sizes of these genes (less than 1000 base pairs on 201 average). Lineage information was generated by TaxonKit and allowed for categorization of hits by virus 202 type and family. 
ii. Targeted searches for ancient core genes in dsDNA viruses. In the second approach, the set of ORFs

204 with viral hits from each wasp species were then queried for the presence of ancient core genes. In order

205 to do this, Hidden Markov Models were constructed for six ancient core genes (DNApol, helicase, lef-5,

206 lef-8, lef-9, and $p 33$, Wang et al. 2012) to find deeply divergent matches. Protein sequences were collated

207 for 24 representative viral species: AcMNPV, CpGV, NeseNPV, CuniNPV, ToNV, OrNV, HzNV-2,

208 PmNV, DiNV, GbNV, GpSGHV, MdSGHV, LbFV, WSSV, CoBV, AMEV, MSEV, VACV, IIV-6, LDV1,

209 HvAV-3e, PbCV1, ApMV, and HHV-3. Sequences were aligned using MUSCLE v3.8.31 (for use as

210 PSSMs in PSI-BLAST) and made into HMMs using hmmbuild within HMMER v3.1b1 (Eddy 2011;

211 Edgar 2004). HMMs were searched against ORFs with viral hits from each species using hmmsearch. The

212 dispersed nature of genes in all parasitoid EVEs discovered to date make it likely that at least some

213 virus-derived genes would be recovered, even though some genomes were poorly assembled

214 (Supplementary Table 3).

215 iii. Detailed annotation of EVEs using homology to other EVE sequences. If sets of virus-derived

216 genes were confidently identified in a wasp genome assembly using the above methods, more detailed

217 annotation was employed for these species. Post hoc searches of wasp genome assembly ORFs against

218 the previously excluded replication genes from bracovirus, ichnovirus, and other parasitoid EVEs were

219 employed to further identify virus-derived genes that may not have been found in earlier searches due to

220 sequence divergence from viral ancestors. To effectively identify virus-derived genes in wasp genomes

221 expected to contain bracoviruses or ichnoviruses, several publicly available reference datasets were

222 employed. The genes encoding the nudivirus-like structural components of bracovirus virions have been

223 completely catalogued in Microplitis demolitor and partially in Cotesia congregata (both subfamily

224 Microgastrinae 53myo) and Chelonus inanitus (subfamily Cheloninae, 85myo) (Murphy et al. 2008;

225 Bezier et al. 2009; Burke et al. 2014). The genes contributing to the production of ichnoviruses known as

226 Ichnovirus Structural Protein Encoding Regions (IVSPERs) have been identified previously in wasps 
227 from the subfamily Campopleginae (Hyposoter didymator) and the subfamily Banchinae (Glypta

228 fumiferanae) (Béliveau et al. 2015; Volkoff et al. 2010). Protein sequences from nudivirus-like replication

229 genes from M. demolitor, C. congregata, and C. inanitus, and separately, protein sequences from

230 IVSPERs in the ichnovirus-producing wasp species Hyposoter didymator and Glypta fumiferanae were

231 added to the custom diamond database described above. All ORFs from each species were searched

232 against the modified database (as above), and ORFs with top hits to sequences from bracovirus-producing

233 or ichnovirus-producing wasp species were extracted from the output. Finally, when genes related to

234 similar virus pathogens were found in multiple wasp genomes, these genes and surrounding ORFs were

235 searched among the multiple wasp genomes to further identify and annotate virus-related genes.

236 iv. Metrics used to determine whether virus-derived sequences are endogenous. Virus-derived

237 sequences identified in wasp genome assemblies could be indicative of EVEs or "contamination" by

238 sequences derived from an actively replicating viral infection. The latter would have a self-contained viral

239 genome, ie. contigs could be assembled into a single, circular or linear dsDNA chromosome representing

240 the viral genome of a non-integrated infectious virus. Features of genome architecture and sequencing

241 metrics were used to build support for the hypothesis that virus-derived sequences are integrated into a

242 given wasp genome. First, it was determined whether virus-derived genes were interspersed among

243 non-viral genes in the wasp genome. Virus-derived genes with "viral architecture" were defined as genes

244 that had homology to genes in viral genomes, are short and most often intronless. Non-viral genes were

245 defined as having homology to hymenopteran or other animal genes and had "eukaryotic architecture";

246 comprising longer genes most often containing introns. If novel virus-derived genes were identified in a

247 wasp genome assembly, scaffolds upon which viral genes were identified were annotated with MAKER v.

248 3.01.02-beta for eukaryotic genes (Holt \& Yandell 2011) and Prokka v. 1.12 for virus-derived genes

249 (Seemann 2014) to see if there were clear signatures of flanking genes with eukaryotic architecture. If

250 available, sequence expression data were aligned to gene annotations with GMAP v.2019-05-12 (Wu \& 
251 Watanabe 2005) to determine whether they were expressed and represent high-confidence annotations.

252 Second, unless extremely recently derived, EVEs are expected to be present in all individuals and

253 populations of a given species of wasp. If available, different versions of wasp genome assemblies

254 generated from geographically distinct populations of wasps were queried for homologous viral genes

255 with BLAST (Altschul et al. 1997). Third, characteristics of contiguous blocks of virus-derived genes

256 were used to assess whether they were likely to be derived from EVEs or an actively-replicating virus

257 infection. Most core replication genes are present as a single copy in insect viral pathogens with dsDNA

258 genomes (Yutin et al. 2009) whereas degraded, pseudogenized forms of viral genes can be found in

259 genomes with EVEs. Finally, sequence read coverage and GC content of contigs were used as further

260 lines of evidence for differentiation of endogenous vs. replicating viral sequences. As EVEs are integrated

261 into wasp genomes, the sequence read coverage of contigs containing EVEs is expected to be similar to

262 other contigs. However, high coverage could be observed from local chromosomal amplification of

263 EVEs, which is known to occur in several parasitoid wasps (Burke et al. 2015; Louis et al. 2013; Di

264 Giovanni et al. 2020). Coverage that is higher or lower than wasp genome contigs could also be an

265 indication of the presence of viral DNA contaminating the insect DNA sequenced. EVEs that represent

266 ancient integration events (such as bracoviruses, Burke \& Strand 2012) are expected to have a GC content

267 similar to the remainder of the wasp genome, while differing GC content between contigs with

268 virus-derived genes and others could be indicative of recently acquired EVEs (whose ancestors may have

269 had differing GC content) or actively replicating viral contaminants. These metrics were used when

270 available and in conjunction with each other to provide an overall picture of the likelihood that

271 virus-derived genes represent EVEs.

272

273 Phylogenetic analyses to determine the closest known relatives of EVEs. To make single gene trees,

274 amino acid sequences from ORFs with viral hits and from endogenous viruses in wasp genomes were 
275 added to sequences from representative taxa used to make PSSMs and HMMs as above. BLAST against

276 the NCBI nr database was used to identify any additional endogenous viral genes from parasitoid wasps

277 to include in alignments. Protein sequences from the EVEs in Glypta fumiferanae and p33 sequences

278 from nimaviruses were excluded because they were extremely divergent and decreased alignment quality.

279 Sequences were aligned using the MAFFT einsi algorithm (Katoh \& Standley 2013), and maximum

280 likelihood phylogenies were derived using the RAxML with the PROTGAMMALG model using default

281 parameters and 100 bootstrap replicates (Stamatakis 2014).

282 A multi-gene phylogeny of NALDV representatives was generated by aligning protein sequences

283 with MUSCLE (Edgar 2004), concatenated with FASconCAT-G (Kück \& Longo 2014) and trimmed with

284 default parameters and a gap threshold of 0.6 by TrimAl (Capella-Gutierrez et al. 2009). A maximum

285 likelihood phylogeny was constructed for the concatenated alignment using RAxML with default

286 parameters and 1,000 rapid bootstrap replicates in the CIPRES portal (Miller et al. 2010). 


\section{Results}

288

\section{Sequencing and assembly generated 11 new draft genome sequences for parasitoid wasps}

290 To accomplish the objective of identifying known and novel EVEs in parasitoid genomes, it was

291 necessary to screen new genomic data for a range of wasp species that had both expected and unknown

292 presence of EVEs (Table 1, Figure 1). In the literature, it is taken for granted that EVEs are present within

293 entire clades of parasitoid species (for example, the microgastroid lineage of Braconidae or the

294 Campopleginae or Banchinae subfamilies of the Ichneumonidae), which sets up expectations for the

295 identification of EVEs in particular species with newly-generated genome assemblies (Table 1, Figure 1).

296 For newly sequenced taxa, it was expected that bracovirus genes would be found within Phanerotoma sp.

297 (subfamily Cheloninae in the microgastroid lineage) and ichnovirus genes (e.g. IVSPER genes) within

298 Lissonota sp. (Banchinae) and Dusona sp. 2 (Campopleginae, hereafter Dusona sp). It was unknown

299 whether the remaining eight species would have EVEs in their genomes.

300 Illumina read counts from the 11 newly added genomes ranged from 58.9 - 88.7 million per library

301 (Supplementary Table 2). Given that the sequence data were generated from short insert libraries only, the

302 assemblies yielded many contigs (ranging from 13,843 to 423,888) with relatively low N50 values $(1,110$

303 to 31,843 nucleotides) compared to the current standard for complete insect genome sequences that

304 employ scaffolding with large insert sequencing libraries or long-sequence read technologies

305 (Supplementary Table 1). The cumulative sizes of scaffolds (a proxy for genome size) was similar for new

306 and previously published high quality assemblies. BUSCO analysis revealed variation in the level of

307 completeness of each new genome assembly, ranging from detection of $98.7 \%$ complete BUSCOs in

308 Meteorus to detection of $26.8 \%$ complete and $46.4 \%$ fragmented BUSCOs (total $73.2 \%$ ) in Anoncus

309 (Supplementary Table 3). Although some genome assemblies were relatively fragmented, overall the

310 amount of sequence data was likely enough to cover a majority of the genomes of these wasps. 


\section{Identification of genes of viral origin using exhaustive sequence similarity searches is fraught with}

\section{3 false positives}

314 To identify genes responsible for making virions or VLPs in wasp genomes, a method to identify

315 endogenous virus elements (EVEs) derived from diverse large double-stranded DNA viruses was needed.

316 Although actively replicating viruses and lateral transfers of single genes from viruses into eukaryotic

317 hosts can generate novel phenotypes of key importance (Parker \& Brisson 2019; Coffman et al. 2020;

318 Aswad \& Katzourakis 2012; Dunlap et al. 2006; Lavialle et al. 2013), the focus here is upon identification

319 of sets of viral replication genes that could be responsible for the production of virions or VLPs that are

320 permanent key components of wasp biology and parasitism success. Homology searches of all ORFs

321 extracted from genome assembly scaffolds against a custom database produced viral hits for 37 to 75

322 ORFs for species with previously published genomes, and 10 to 53 ORFs for new species (Supplementary

323 Figure 1 and 2, Supplementary Table 4). Hits were to viruses belonging to several major groups: dsDNA

324 viruses, ssDNA viruses, ssRNA viruses, dsRNA viruses, Ortervirales, and unclassified viruses. As all

325 genetically characterized examples of virions or VLPs produced by parasitoid wasps thus far originate

326 from large dsDNA viruses, hits to other types of viruses were not analyzed further in this study. Most hits

327 were to the dsDNA viruses, particularly to the families Nudiviridae, Baculoviridae, Poxviridae,

328 Ascoviridae, Hytrosaviridae, Iridoviridae, and the Caudovirales. However, manual inspection of the

329 annotations associated with these hits revealed that many of these proteins are retroviral proteins,

330 inhibitor of apoptosis proteins, chitosanases, and transposases (Supplementary Table 4). These genes do

331 not encode the necessary components for building virions or virus-like particles, and are frequently

332 transferred between viruses and eukaryotes. Therefore, many or most of these genes have obscure origins

333 and are unlikely to play a role in producing virions or VLPs that contribute to wasp parasitism success. 


\section{Targeted searches for ancient core genes can accurately identify EVEs likely to produce virions or}

\section{VLPs in wasp genomes}

337 The preceding results indicated that a different approach was necessary to identify sets of

338 virus-derived genes that are likely to be involved in producing virions or virus-like particles.

339 Double-stranded DNA viruses that infect insects can be categorized into several virus families belonging

340 to at least two major groups, the monophyletic Nuclear Cytoplasmic Large DNA Viruses (NCLDVs) and

341 Nuclear Arthropod-specific Large DNA Viruses (NALDVs) (Iyer et al. 2001; Wang et al. 2012). While

342 viruses generally use a very diverse set of strategies for replication, there exist at least six genes encoding

343 replication components that are common to NALDVs and NCLDVs (Wang et al. 2012). These genes are

344 present in most extant members of major families of viruses in these groups and are referred to as ancient

345 core genes (although they may not share a common origin, Iyer et al. 2006; Wang et al. 2012).

346 To produce the key components necessary for the completion of virus replication and

347 construction of virions or VLPs, it was rationalized that wasp genomes would need to contain at least

348 some of the ancient core genes. To identify the presence or absence of ancient core genes, each set of

349 ORFs with viral hits generated by the exhaustive method above was searched with methods that can

350 detect homologs with very low sequence similarity by focusing upon patterns of conserved sites among

351 protein sequences. While genes encoding ichnovirus replication machinery may be related to NCLDV

352 core genes, the protein sequences from IVSPERs were too divergent to be incorporated into our search

353 strategies. Thus, searches for ancient core genes are expected to identify EVEs derived from NCLDVs

354 and NALDVs, but not the ancestors of ichnoviruses.

355 PSI-BLAST and HMM searches among putative viral protein sequences from each wasp species

356 identified a total of 11 homologs of ancient core genes in new genome assemblies and 22 in previously

357 published genome assemblies (Table 2, Supplementary Table 5). Previously published genome sequences

358 known to contain EVEs served as positive controls for the identification of ancient core genes using the 
method described here that relies upon limited homology from deep divergence events. Previous work

360

361

362 lost in wasp species with EVEs, Burke 2019). Homology searches identified genes encoding helicase,

363 lef- 8 , lef- 9 and $p 33$ proteins in the set of putative viral proteins for each positive control species.

364 However, lef-5 was identified in F. arisanus only, and could not be identified in the two other species

365 even when the full set of ORFs from each species was searched. This may be due to limited sequence

366 similarity and the short sequence length of lef-5 genes reducing the success of PSI-BLAST and HMMR

367 searches targeting very diverse taxa. Although C. vestalis females are known to produce bracovirus in

368 their ovaries, no publication has yet provided a detailed annotation of EVEs in the C. vestalis genome.

369 ORFs with homology to viral helicase, lef-8, and lef-9 genes were identified, as well as a viral DNA

370 polymerase (DNApol), warranting further exploration of genes of viral origin in this species (see below).

371 Two previously published wasp genomes that are not known to contain EVEs (D. alloeum and M.

372 cingulum) were negative for all ancient core genes. These results indicate that PSI-BLAST and HMMR

373 can reliably detect the presence or absence of viral ancient core genes in wasp genomes.

374 In new wasp genomes, identification of at least one ancient core gene provided enough evidence

375 to justify further exploration, while the absence of any hits led to the conclusion that specific wasp species

376 are unlikely to produce virions or VLPs and exclude these species from further analysis. Proteins encoded

377 by ancient core genes were identified in Dolichomitus (DNApol, helicase, lef-8, lef-9), Dusona (lef-8,

378 lef-9), and Phanerotoma (lef-8, lef-9, p33).

379 Manual examination of protein alignments for each putative ancient core gene identified in wasp

380 species (aligned with homologs from representative large DNA viruses and EVEs) confirmed protein

381 identity and revealed that almost all hits were full length. Exceptions included one of the two DNApol

382 genes from C. vestalis and one of the two lef-9 genes from Dolichomitus. Lef- 8 sequences from 
Phanerotoma and Dolichomitus each had two ORFs matching this protein (N-terminal and C-terminal

384 fragments). The Phanerotoma coding sequences lie on two different contigs, likely indicating broken

385 assembly, and the Dolichomitus sequences lie near each other, suggesting that they are pseudogenized.

386 The matches from Dusona were ORFs that were truncated compared to full length lef- 8 and lef- 9

387 sequences, and came from short scaffolds with low coverage, so were excluded from further analysis as

388 likely contaminant sequences.

389 Phylogenetic reconstruction of ancient core gene trees revealed that genes of viral origin in each

390 new wasp genome assembly came from a variety of sources (Figure 2, Supplementary Table 6). As

391 expected, Phanerotoma lef-8, lef-9, and $p 33$ sequences grouped with the bracoviruses. Dolichomitus

392 DNApol, Helicase, lef-8, and lef-9 sequences all grouped with protein sequences from Leptopilina

393 boulardi Filamentous Virus (LbFV), a large double-stranded DNA virus that is distantly related to

394 hytrosaviruses and may represent a distinct virus family (Lepetit et al. 2017). The C. vestalis genome

395 contains at least two ORFs of viral origin for $l e f-8$ and lef- 9 each. C. vestalis sequences fell into two

396 groups: sequences clustered with bracoviruses (helicase, lef-8, and lef-9) or with LbFV (DNApol, lef-8,

397 and lef-9). These data indicate that the sequenced C. vestalis samples contain two separate sources of viral

398 genes; bracoviruses and a LbFV-like entity.

\section{Bracovirus nudivirus-like replication genes were detected in species in the microgastroid complex}

401 As described above, bracoviruses were expected in the previously unannotated C. vestalis

402 genome assembly and the new Phanerotoma genome assembly. These findings provide two

403 proof-of-concept datasets to validate the approach for the identification of nudivirus-like replication genes

404 beyond just the ancient core genes. Although genes from proviral segments are undoubtedly present in the

405 datasets, their annotation was not attempted due to the fragmented nature of the genome assemblies and

406 the lack of conserved genes that could be used as a proviral segment diagnostic. The first strategy used for 
the identification of nudivirus-like replication genes involved alignment of ORFs from each genome

408 assembly to the custom diamond database. The second strategy was designed to identify an expanded set

409 of nudivirus-like EVEs in each genome assembly, and involved adding nudivirus-like replication genes

410 from M. demolitor, C. congregata, and C. inanitus to the custom diamond database and repeating the

411 diamond search. The existing nudivirus-like replication gene models from bracoviruses are the products

412 of careful manual annotation of sequence data. These manually curated sequences are more likely to

413 generate database search hits compared to searches against the set of insect virus genomes available in

414 public databases because they are less divergent than other nudiviruses; these genes are the products of a

415 single integration event and share a common ancestor 100mya (Murphy et al. 2008).

416 Using the first search strategy, 18 ORFs similar to nudivirus and baculovirus genes were

417 identified on 18 contigs in the Phanerotoma assembly ranging in size from 885bp to $12,791 \mathrm{bp}$. The GC

418 content of these contigs was not significantly different from BUSCO-containing contigs, but on average

419 their coverage was slightly higher (Supplementary Figure 2, 28x compared to 9x, $p<0.05$ ). The second

420 strategy for identification of nudivirus-derived genes found 13 of the original 18 ORFs plus 37 additional

421 genes (55 total, Supplementary Table 7). A search of all ORFs in the C. vestalis genome against the

422 custom diamond database revealed 29 ORFs matching to nudivirus or baculovirus coding sequences

423 located on 24 contigs. The GC content of contigs containing nudivirus-like genes was not significantly

424 different than BUSCO-containing contigs (mean 29.7\% compared to $29.2 \%$, respectively, $p=0.30$ ). It

425 was not possible to create scaffold coverage and GC content plots for $C$. vestalis, because the sequencing

426 reads used to make the genome assembly were not available in the NCBI Sequence Read Archive. A

427 broader search using the second strategy as described above identified 13 of the original 29 ORFs, plus an

428 additional 78 hits (106 total, Supplementary Table 7).

429 To assess the completeness of the set of bracovirus replication genes identified in each assembly,

430 a tally of the genes conserved in bracoviruses and also nudiviruses that are presumed to be essential for 
431 virion production was conducted. The M. demolitor genome contains at least one copy of 19 of the 33

432 nudivirus core genes (18 of these are also core genes in baculoviruses, Burke 2019). All of the 19 genes

433 conserved in nudiviruses and M. demolitor were present in the set of nudivirus-like genes identified in

434 Phanerotoma, and only one gene, pif-4, was missing in the C. vestalis assembly. These results indicate

435 that the methods used were appropriate for the identification of the presence of EVEs that are likely to

436 produce bracoviruses. However, the genome assemblies were sufficiently fragmented that there was not

437 enough information to confidently assess the placement of genes or the presence of synteny between

438 nudivirus-like genes in microgastroid species. The fragmented nature of the new genome assemblies and

439 the coarse nature of the methods used made it possible that a complete list of EVE genes in the

440 Phanerotoma and C. vestalis genomes was not fully identified. A more detailed and comprehensive

441 analysis will be appropriate if and when assemblies with larger scaffold sizes are available for these

442 species.

443

444 Ichnovirus Structural Protein Encoding Regions (IVSPERs) were detectable but not always present

445 where expected

446 Given that no ancient core genes have been documented as consistently present in

447 ichnovirus-producing wasp genomes to date, the strategy used for the identification of IVSPER genes in

448 wasp genome assemblies relied upon homology to the IVSPERs from H. didymator and G. fumiferanae.

449 IVSPER genes were identified in the Lissonota genome assembly associated with ten scaffolds ranging in

450 size from 1,227bp to 44,485bp (Supplementary Figure 2). The protein sequence percentage identity to $G$.

451 fumiferanae IVSPER genes from diamond searches was $28-86 \%$, with an average of $57 \%$. Like the

452 scaffolds containing EVEs in F. arisanus and M. demolitor, in Lissonota the IVSPERs were located on

453 scaffolds that did not significantly differ in coverage from scaffolds that contain BUSCO genes

454 (Supplementary Figure 2). This indicates that as in other IV-producing wasps, the IVSPER genes are 
455 integrated into the genome of Lissonota (Béliveau et al. 2015; Volkoff et al. 2010). Scaffolds containing

456 IVSPERs had a slightly higher GC content (39.7\%) compared to BUSCO scaffolds $(37.8 \%, p<0.05)$.

457 Lissonota IVSPERs had high levels of synteny with IVSPERs previously identified in the banchine $G$.

458 fumiferanae, indicating that the viral integration event occurred in a shared ancestor of these wasp species

459 (Figure 3). Twenty-four genes were shared between these two species and were also present in the

460 IVSPERs in H. didymator, while another 25 were present in the two banchine species only. The four

461 genes linking IVs to NCLDVs (ssp1, DNApol, D5 primase, and helicase) were present in Lissonota as

462 well as G. fumiferanae, where they were discovered.

463 There were no significant hits to any ORFs from the remaining ten new genome assemblies or the

464 previously published genome assemblies. The only exception was a match to a hypothetical protein (U44,

465 AKD28091.1) in the V. canescens, M. cingulum, F. arisanus and Lissonota ORFs. BLAST of the G.

466 fumiferanae $\mathrm{U} 44$ revealed that this protein has strong similarity to other hymenopteran proteins, making it

467 unclear whether the ORFs identified are viral in origin, or merely wasp genes. The absence of hits to

468 IVSPER genes in Dusona is notable because this species belongs to the Campopleginae, where all taxa

469 were assumed to have ichnoviruses. The absence of IVSPERs and related genes in Mesochorus

470 (Mesochorinae) and Anoncus (Ctenoplematinae) is also notable as they share a common ancestor with the

471 Campopleginae and Banchinae. In addition, the absence of IVSPERs in Dusona suggest that IVs might

472 actually be limited to a subset of species within the campoplegine wasps.

473

474 Novel filamentous virus-like genes were identified in the $C$. vestalis and Dolichomitus genomes

475 The identification of several ancient core genes related to LbFV genes in the C. vestalis and

476 Phanerotoma genomes provided a strong hint that these species contain EVEs or are "contaminated" with

477 sequences from an actively replicating viral infection. This result motivated expansion of the search for

478 LbFV-like genes beyond the ancient core genes initially identified to look for signatures of wasp genome 
479

480

490 LbFV genes were identified on three C. vestalis genomic scaffolds (Figure 4, accession doi:

491 10.15482/USDA.ADC/1504545). DNApol, lef-4, lef-8, lef-9 and 25 other neighboring genes encoding

492 hypothetical proteins with typical viral architecture (short, closely spaced, no introns) are located on the

493 first scaffold (JZSA01000885.1) next to four eukaryotic genes encoding uncharacterized proteins: two

494 with similarity to hymenopteran species and another with similarity to Helicoverpa armigera. The second

495 scaffold (JZSA01004450.1) contains a partial (50\% full length) copy of a viral DNApol gene situated

496 among seven genes with eukaryotic architecture and strong similarity to other hymenopteran genes,

497 including syntaxin-7, adenylate cyclase type 2, importin-4, and forkhead box-like genes (Figure 4). The

498 final scaffold (JZSA01007324.1) contains lef-3, 38K, p74, pif-2, pif-5, ac81, odv-e66, putative

499 lecithin:cholesterol acyltransferase genes and 52 other genes with viral architecture. Interspersed are two

500 genes that have eukaryotic architecture with significant similarity to genes encoding uncharacterized

501 proteins in other hymenopteran species (Figure 4). Alignment of sequence expression data provided

502 evidence that 6 of the 13 eukaryotic genes are expressed and thus represent high-confidence annotations. 
The overall organization of genes in these loci suggest that LbFV-like genes are present in the

504 wasp genome in three different locations; two likely representing primary integration events constituting

505 large portions of the LbFV-like ancestor's genome, and the third possibly representing a secondary

506 integration event in which part of the viral DNApol gene was transferred to a different region of the wasp

507 genome. For both of the putative primary integration events, the ends of strings of genes of with viral

508 architecture are associated with remnants of retroviral genes such as pol, gag-pol, and gag-pro-pol,

509 suggesting retroelements as a possible source for entry of viral genes into the wasp genome (Desjardins et

510 al. 2008).

511 Two genome assemblies are available for C. vestalis on NCBI. The two assemblies were

512 generated from wasp populations located in Andong, South Korea (ASM95615v1) and Hangzhou, China

513 (ASM167554v1). Full length versions of all of the genes of viral origin were present in both assemblies

514 (except ac81, which was only present at $80 \%$ length in the Hangzhou assembly, located at the end of a

515 scaffold) with nucleotide sequence identity ranging from 97-99\%. The presence of slightly divergent

516 genes of viral origin in both assemblies further suggests that these genes are integrated into the wasp

517 genome for both populations of C. vestalis.

518 A total of 18 contigs in the Dolichomitus genome assembly (ranging in size from $312 \mathrm{bp}$ to

$51939.5 \mathrm{~kb}$ ) contained genes related to LbFV. These contigs were too short in length to determine whether any

520 genes with eukaryotic architecture were flanking the virus-derived genes. The GC content of these contigs

521 was significantly lower than BUSCO-containing contigs (mean $37.4 \%$ compared to $39.6 \%, p<10^{-4}$ ), and

522 on average their coverage was higher $\left(28 \mathrm{x}\right.$ compared to $7 \mathrm{x}, p<10^{-9}$ on $\log _{10}$ transformed values,

523 Supplementary Figure 2). After manual annotation of these contigs, diamond analysis revealed that 24 of

524 the total 149 ORFs had similarity to LbFV genes, including DNApol, lef-3, lef-4, lef-5, lef-8, lef-9, pif-0,

525 pif-1, pif-2, pif-3, pif-5, 38K, helicase, helicase2, and ac81 (Figure 5). Although the cumulative size of the

526 "viral" contigs was $199 \mathrm{~kb}$, the non-degenerate size was approximately $114 \mathrm{~kb}$ because many contigs were 


\section{7} repetitive, with up to three divergent copies of distinct genes present among the set (Figure 5). BLAST

\section{8} alignment identity for LbFV genes to Dolichomitus ORFs ranged from 22.9-42.7\% (mean 31.2\%, median $32 \%$ ), while identity among paralogous Dolichomitus ORFs was $30.4-95.83 \%$ (average $62.8 \%$, median 62.9\%). Comparison of the Dolichomitus and C. vestalis genes with viral architecture flanking LbFV-like genes revealed homologs of six genes that are common to the two wasp genome assemblies but are not

532 present in LbFV, and were given the gene names Filamentous Virus Unknown (FVU) 1 through 6 (Figure 533 5). The divergence of viral genes in Dolichomitus compared to LbFV often made it difficult to determine 534 whether an ORF represents a full-length gene. However, homology between ORFs on different contigs in 535 Dolichomitus revealed that some ORFs represent fragments of pseudogenized genes (Figure 5). Of all of 536 the ORFs predicted on the 18 Dolichomitus contigs, 33 are fragments of a total of 14 pseudogenized 537 genes (ranging from 1 to 6 per contig). On three contigs, core genes that are considered essential for 538 replication were inactivated: $38 K$ on Node_1, p74 and pif-5 on Node_10, lef-4 on Node_71 and lef-8 on

539 NODE_820. The presence of degenerated essential genes provides strong evidence that at least these four 540 LbFV-like contigs are endogenous in the Dolichomitus genome. These contigs are not likely to be part of 541 an archetypal virus genome actively replicating in Dolichomitus, because the products of these genes 542 would be non-functional or absent and are essential for virion formation. The presence of several 543 syntenous copies of viral genes could be the product of multiple integration or genome locus duplication 544 events that have substantially diverged over time. If all of the LbFV-like contigs were endogenous in the 545 Dolichomitus genome, it is noted that at least one copy of each LbFV-like gene with essential functions 546 was intact across the contigs cumulatively. Thus, it is theoretically possible that this Dolichomitus wasp 547 produced virus-like particles by assembling protein products from intact LbFV-like genes that are 548 dispersed throughout the Dolichomitus genome.

\section{9}

550 EVEs in parasitoid wasp species are distantly related to other arthropod DNA viruses 
After annotation of the genes of viral origin in all of the new wasp genome assemblies, a list of 552 genes emerged as conserved in many if not all viruses and EVEs derived from within the NALDVs. In

553 addition to the ancient core genes (DNApol, helicase, lef-5, lef-8, lef-9, and p33), the recent description of 554 nimavirus EVEs present in crustacean genomes identified pif-0, pif-1, pif-2, pif-3, and pif5 as core genes 555 present in NALDVs (Kawato et al. 2018). Based upon new data from EVEs related to LbFV, ac81 can be 556 added to a core gene set for viruses that infect insects (Supplementary Table 8). Protein sequences from 557 these 12 genes were used to construct a multi-gene phylogeny and examine the relationships between 558 viruses and EVEs (Figure 6).

560 related to each other, as were bracoviruses from both wasps belonging to Cotesia within the

561 Microgastrinae (C. congregata and C. vestalis) (Figure 6). The EVEs related to LbFV are referred to as 562 Dolichomitus Endogenous Filamentous Virus (DoEFV) and C. vestalis Endogenous Filamentous Virus 563 CvEFV). These EVEs are as divergent from each other as they are from LbFV. Despite their names, the 564 filamentous viruses from L. boulardi and A. mellifera are separated on the phylogeny by hytrosaviruses 565 and do not appear to belong to the same virus family (Figure 6).

\section{Discussion}

569 This study investigated the presence and distribution of EVEs in one of the most astonishing 570 radiations on Earth (parasitoid wasps from the Ichneumonoidea) and hints at the massive untapped

571 number and diversity of viral acquisition events. As of early 2019 when this study began, only five

572 genomes from the Ichneumonoidea were available in the National Center for Biotechnology Information 573 database, but with advances in sequencing technologies, rapid growth of this number is expected. The 574 availability of genome sequence data from 11 new species representing diverse lineages from within the 
575 Ichneumonoidea provided a unique opportunity to identify genes of viral origin. The identification of sets

576 of genes involved in viral replication is suggestive of the production of virions or VLPs that have a

577 significant impact upon parasitoid wasp biology. Further, characterizing the presence or absence of EVEs

578 in relatives of wasp species known to produce virions or VLPs provides information about the origination

579 of these features and their species distribution.

580 A new approach was needed in order to screen wasp genomes for genes of viral origin in a

581 consistent and high-throughput manner. The approaches designed here were validated using six

582 previously published genomes from the Ichneumonoidea with known presence or absence of EVEs. The

583 first, simplest approach used to identify genes of viral origin was to screen all ORFs against a streamlined

584 form of the NCBI nr database. However, this screen resulted in false positives due to the presence of

585 many hits to viral genes that are likely to be frequently transferred between eukaryotic and viral genomes.

586 The second approach therefore focused upon identification of ancient core genes, or genes that serve

587 essential functions in the production of virions in dsDNA viruses. With this approach, it was possible to

588 verify the presence of bracoviruses in the previously published genomes of M. demolitor and C. vestalis.

589 The presence of genes derived from nudivirus acquisition events was also recovered with this method in

590 F. arisanus and $V$. canescens. The ancient core gene approach also accurately showed that there are no

591 virus gene acquisitions in the D. alloeum or M. cingulum genomes.

592 Having established a method that could pinpoint which species to focus upon further, the new

593 genome assemblies were searched for the presence of ancient core genes. If ancient core genes were

594 identified, their evolutionary history was reconstructed with phylogenetic trees with representatives of the

595 diversity of large dsDNA viruses. Ancient core genes are not necessarily monophyletic, in fact, many

596 seem to be acquired from eukaryotic replication systems independently in NALDVs and NCLDVs (Iyer

597 et al. 2004, 2006, 2003; Kool et al. 1994). Thus, the weak support at basal nodes of the phylogenetic trees

598 in Figure 2 was expected, and rather than attempting to elucidate relationships between ancient 
divergence events in viral evolution, these trees functioned to categorize viral endogenization events into

600

601

602 ichnovirus in the banchine ichneumonid, Lissonota. The screen for ancient core genes then identified two

603 major findings that were not expected a priori: 1) the presence of LbFV-related genes in C. vestalis

604 (Braconidae: Microgastrinae) and Dolichomitus (Ichneumonidae: Pimplinae) genomes, and 2) the absence

605 of an ichnovirus in the campoplegine ichneumonid, Dusona. The preceding results will be discussed

606 further below.

607

608 Both nudiviruses and LbFV-like viruses are common endogenous virus progenitors

609

Prior to this study, endogenous viruses discovered in parasitoid wasp species revealed that virus

610 co-option from nudivirus ancestors has occurred independently on at least four occasions (Bezier et al.

611 2009, Burke et al. 2018, Pichon et al. 2015, Zhang et al. 2020), all in koinobiont endoparasitic wasps. Out

612 of all of the major groups of insect-infecting viruses, the predominance of nudivirus ancestors of EVEs

613 suggested specific, as yet unknown conserved features of nudiviruses may predispose this group to

614 integration and establishment in wasp genomes (Strand \& Burke 2020, 2014). Recently, the first

615 endogenization event from an ancestor other than nudiviruses and the ichnovirus ancestor was identified

616 in Leptopilina boulardi (Figitidae), a koinobiont endoparasitoid wasp that produces VLPs or Mixed

617 Strategy Endocytic Vesicles (MSEVs) (Di Giovanni et al. 2020; Heavner et al. 2017; Rizki \& Rizki

618 1990). The ancestor of the EVE in L. boulardi (henceforth referred to as LbEFV) was a

619 behavior-manipulating filamentous virus that also infects L. boulardi (LbFV), although the two are

620 relatively distantly related (Di Giovanni et al. 2020). This virus was only recently identified and although

621 it clearly belongs to the NALDVs, it is so divergent from other virus families that it most likely represents

622 the first discovered member of a new virus family (Lepetit et al. 2017). 
624 entity into parasitoid wasp genomes, making LbFV-like viruses a second group of viruses that seem to be

625 predisposed to endogenization. Both C. vestalis and Dolichomitus possess intact versions of many of the

626 genes necessary to make virions or VLPs, justifying future investigation of the reproductive secretions of

627 these wasp species. The LbFV-like virus in Dolichomitus also represents the first endogenized virus in an

628 idiobiont ectoparasitoid, suggesting that this virus may function differently for parasitism success.

629 Additionally, given that $C$. vestalis already produces a bracovirus, investigation of the role of LbFV-like

630 genes in this species could address whether LbFV-like virions are also produced and how both types of

631 virus might impact parasitism success and/or behavior. It is noted that non-bracovirus filamentous

632 particles have been observed in Cotesia species previously. Filamentous virions with similar morphology

633 have been observed in C. congregata and C. marginiventris (as well as the ichneumonid Eriborus

634 terebrans (formerly Diagema terebrans) (Styer et al. 1987; Hamm et al. 1990; Krell 1987; Townes 1965).

635 Although no genetic data are available for the filamentous viruses in other Cotesia species, these viruses

636 and LbFV have similar morphogenesis (capsid production in cell nuclei, acquisition of an envelope in the

637 cytoplasm) and may be derived from the same type of viral ancestor (Varaldi et al. 2006; Buron et al.

638 1992).

639

\section{0 "Ichnoviruses" represent two independent, relatively recent virus acquisition events}

641 The genus "Ichnovirus" was coined to describe a type of virus that replicates in wasp ovaries and

642 is injected into host insects during oviposition (Lefkowitz et al. 2018). This type of virus had a lenticular

643 capsid surrounded by two unit membrane envelopes and a polydisperse genome including multiple

644 double-stranded, circular DNAs of different sizes and coding capacities (Stoltz et al. 1984). At that time,

645 it was not known that ichnoviruses were actually heritable endogenous entities, unlike archetypal viruses.

646 It is more appropriate to group and name EVEs according to their independent evolutionary origins, 
647 which requires knowledge of the evolutionary history of wasp species that possess EVEs. The

648 hyperdiversity of species within the Ichneumonidae has made their evolutionary relationships historically

649 difficult to resolve. However, recent studies (Quicke et al. 2009; Klopfstein et al. 2019; Bennett et al.

650 2019) have confirmed results from a single gene phylogeny to show that Campopleginae and Banchinae

651 are not closely related to each other. Two previous studies have described the IVSPERs in a single

652 member of each of these subfamilies, and from extensive overlap of the catalogue of IVSPER genes,

653 concluded that these EVEs came from similar, if not identical virus ancestors (Béliveau et al. 2015;

654 Volkoff et al. 2010). Beliveau et al (2015) suggested two evolutionary scenarios giving rise to the

655 presence of IVSPERs in these two divergent wasp subfamilies. First, that there was a single IV ancestor,

656 in which a NCLDV integrated into the genome of an ancestor of banchine and campoplegine wasps. If no

657 IVs are observed in wasp species belonging to the subfamilies that also descend from the common

658 ancestor of banchine and campoplegine wasps, it implies that the capacity to produce IVs was lost in all

659 of these species, although traces of IVSPER genes could remain in their genomes. The second scenario

660 involves two separate integration events involving very similar viral ancestors (related to NCLDVs) that

661 took place separately in the ancestors of banchine and campoplegine wasps.

662 Our data support the second scenario involving two independent integration events in

663 campoplegine and banchine wasp species. First, based upon the phylogeny generated by Sharanowski et

664 al. (2020), two of the wasp species with new genome assemblies, Anoncus (Ctenopelmatinae) and

665 Mesochorus (Mesochorinae), are “intervening taxa”, ie. they do not belong to either of the IV-producing

666 subfamilies but descend from the common ancestor of these subfamilies. Both of these genomes lack

667 ancient viral core genes, common dsDNA virus replication genes, and IVSPER-like genes, intact or

668 otherwise. Second, the unexpected absence of IVSPERs in Dusona suggests that ichnoviruses are not

669 present in all campoplegine species, and may be limited to a clade containing Hyposoter, Tranosema,

670 Campoletis, and Casinaria while excluding Dusona and possibly Campoplex (Sharanowski et al. 2020, 
671 (Volkoff et al. 2010; Pichon et al. 2015). Determining the distribution of EVEs among species is

672 important because it will help to inform whether other viral acquisition events (such as the nudivirus in

673 the campoplegine $V$. canescens) are truly replacement events or represent acquisition into a wasp ancestor

674 that ancestrally lacked an EVE. Third, the architecture of the IVSPERs within wasp genomes also

675 provides evidence of recent acquisition. The IVSPERs in H. didymator, G. fumiferanae and now

676 Lissonota (all Banchines) are each located in three compact clusters within wasp genomes, respectively.

677 This level of clustering is similar to the architecture observed for the recently-derived endogenous

678 nudivirus in F. arisanus (nine major clusters), and lies in contrast to the extensive spread of nudivirus-like

679 genes in the M. demolitor genome representative of the bracovirus-producing microgastrine wasps (Burke

680 et al. 2014; Burke, Simmonds, et al. 2018; Burke, Walden, et al. 2018). As the spread of virus-derived

681 wasp genes throughout wasp genomes is thought to be a relatively neutral process that occurs over

682 evolutionary time (Burke et al. 2014), the limited spread of the IVSPERs in wasp genomes indicates that

683 their integration occurred relatively recently. Finally, there are morphological differences between the

684 campoplegine and banchine ichnoviruses that also suggest their independent origins (Béliveau et al.

685 2015). While a close relative of the "ichnoviruses" has yet to be discovered in a non-endogenous form, it

686 is possible that the ichnovirus ancestor is also a common progenitor of endogenous associations in

687 parasitoid wasps.

\section{Concluding remarks}

689 This study has shown that sequencing parasitoid wasp genomes can reveal novel instances of

690 EVE acquisitions in the Ichneumonoidea. The generation of new genomic data from just eleven species

691 and re-analysis of six publicly available genomes has identified two independently-derived, novel EVEs.

692 Additionally, the new genomes generated sequence data for two more EVEs that were expected in two

693 species based upon their clade membership. Following the proposed use of a standardized nomenclature

694 toward binomial species names for viruses (ICTV) (Siddell et al. 2020), revision of the genera Bracovirus 
695 and Ichnovirus and the family Polydnaviridae should be considered to reflect their endogenous nature and

696 their evolutionary history. Additionally, coining a name for the LbFV-like viruses would be useful given

697 their prevalence as EVEs in parasitoid wasps. Overall, the data presented in this study hints that the

698 diversity of viral co-option events extends much further and is more common than just two rare, ancient

699 events previously referred to as bracoviruses and ichnoviruses. Rather, the acquisition of EVEs from

700 different groups of viral pathogens creates an ample source of variation for the recurrent evolution of

701 diverse parasitism-based virulence strategies in parasitoid wasps.

702

703

\section{Acknowledgements}

705 The authors would like to acknowledge Michael Strand for feedback upon the manuscript. This work was

706 supported by the US National Science Foundation (DEB-1622986 to G.R.B. and DEB-1916788 to G.R.B.

707 and B.J.S.), the USDA National Institute of Food and Agriculture Hatch project (1013423 to G.R.B.), and

708 the Natural Sciences and Engineering Research Council (NSERC) Discovery Program (B.J.S.).

709

\section{Data availability}

711 The data underlying this article are available in the National Center for Biotechnology Information at

712 https://www.ncbi.nlm.nih.gov, and the Ag Data Commons at https://data.nal.usda.gov, and can be

713 accessed with accession numbers given throughout the manuscript, figures, tables, and supplementary

714 information.

715

716 


\section{References}

718 Altschul SF et al. 1997. Gapped BLAST and PSI-BLAST: a new generation of protein database search

719 programs. Nucleic Acids Res. 25:3389-3402.

720 Askew RR. 1971. Parasitic Insects. Heinemann Educational Books.

721 Aswad A, Katzourakis A. 2012. Paleovirology and virally derived immunity. Trends Ecol. Evol.

722 27:627-636. doi: 10.1016/j.tree.2012.07.007.

723 Bankevich A et al. 2012. SPAdes: a new genome assembly algorithm and its applications to single-cell

724 sequencing. J. Comput. Biol. 19:455-477.

725 Barton ES et al. 2007. Herpesvirus latency confers symbiotic protection from bacterial infection. Nature.

726 447:326-329.

727 Beckage NE, Tan FF, Schleifer KW, Lane RD, Cherubin LL. 1994. Characterization and biological effects

728 of Cotesia congregata polydnavirus on host larvae of the tobacco hornworm, Manduca sexta. Arch. Insect

729 Biochem. Physiol. 26:165-195.

730 Béliveau C et al. 2015. Genomic and proteomic analyses indicate that Banchine and Campoplegine

731 polydnaviruses have similar, if not identical, viral ancestors. J. Virol. 89:8909-8921.

732 Bennett AMR, Cardinal S, Gauld ID, Wahl DB. 2019. Phylogeny of the subfamilies of Ichneumonidae

733 (Hymenoptera). J. Hymenopt. Res. 71:1-156. doi: 10.3897/jhr.71.32375.

734 Bézier A et al. 2013. Functional endogenous viral elements in the genome of the parasitoid wasp Cotesia

735 congregata: insights into the evolutionary dynamics of bracoviruses. Philos. Trans. R. Soc. Lond. B Biol.

736 Sci. 368:20130047.

737 Bézier A et al. 2009. Polydnaviruses of braconid wasps derive from an ancestral nudivirus. Science.

738 323:926-930. doi: 10.1126/science.1166788.

739 Brown SP, Le Chat L, De Paepe M, Taddei F. 2006. Ecology of microbial invasions: amplification allows

740 virus carriers to invade more rapidly when rare. Curr. Biol. 16:2048-2052. doi:

741 10.1016/j.cub.2006.08.089.

742 Buchfink B, Xie C, Huson DH. 2015. Fast and sensitive protein alignment using DIAMOND. Nat.

743 Methods. 12:59-60.

744 Burke GR. 2019. Common themes in three independently derived endogenous nudivirus elements in

745 parasitoid wasps. Curr. Opin. Insect Sci. 32:28-35.

746 Burke GR, Simmonds TJ, Sharanowski BJ, Geib SM. 2018. Rapid Viral Symbiogenesis via Changes in

747 Parasitoid Wasp Genome Architecture. Mol. Biol. Evol. 35:2463-2474.

748 Burke GR, Simmonds TJ, Thomas SA, Strand MR. 2015. Microplitis demolitor Bracovirus proviral loci

749 and clustered replication genes exhibit distinct DNA amplification patterns during replication. J. Virol.

750 89:9511-9523. doi: 10.1128/jvi.01388-15. 
Burke GR, Strand MR. 2012. Polydnaviruses of parasitic wasps: domestication of viruses to act as gene delivery vectors. Insects. 3:91-119.

Burke GR, Walden KKO, Whitfield JB, Robertson HM, Strand MR. 2018. Whole genome sequence of the parasitoid wasp Microplitis demolitor that harbors an endogenous virus mutualist. G3. 8:2875-2880.

Burke GR, Walden KKO, Whitfield JB, Robertson HM, Strand MR. 2014. Widespread genome reorganization of an obligate virus mutualist. PLoS Genet. 10:e1004660.

Capella-Gutierrez S, Silla-Martinez JM, Gabaldon T. 2009. trimAl: a tool for automated alignment trimming in large-scale phylogenetic analyses. Bioinformatics. 25:1972-1973. doi:

10.1093/bioinformatics/btp348.

Chapman AD. 2009. Australian Government Department of the Environment and Energy.

Coffman KA, Harrell TC, Burke GR. 2020. A mutualistic poxvirus exhibits convergent evolution with other heritable viruses in parasitoid wasps. J. Virol. 94. doi: 10.1128/JVI.02059-19.

Darboux I, Cusson M, Volkoff A-N. 2019. The dual life of ichnoviruses. Curr. Opin. Insect Sci. 32:47-53. doi: 10.1016/j.cois.2018.10.007.

de Buron I, Beckage NE. 1992. Characterization of a polydnavirus (PDV) and virus-like filamentous particle (VLFP) in the braconid wasp Cotesia congregata (Hymenoptera: Braconidae). J. Invertebr. Pathol. 59:315-327. doi: 10.1016/0022-2011(92)90139-u.

Desjardins CA et al. 2008. Comparative genomics of mutualistic viruses of Glyptapanteles parasitic wasps. Genome Biol. 9:R183.

Di Giovanni D et al. 2020. A behavior-manipulating virus relative as a source of adaptive genes for Drosophila parasitoids. Mol. Biol. Evol. doi: 10.1093/molbev/msaa030.

Dunlap KA et al. 2006. Endogenous retroviruses regulate periimplantation placental growth and differentiation. Proc. Natl. Acad. Sci. U. S. A. 103:14390-14395.

Eddy SR. 2011. Accelerated Profile HMM Searches. PLoS Comput. Biol. 7:e1002195.

Edgar RC. 2004. MUSCLE: multiple sequence alignment with high accuracy and high throughput. Nucleic Acids Res. 32:1792-1797.

Edson KM, Vinson SB, Stoltz DB, Summers MD. 1981. Virus in a parasitoid wasp: suppression of the cellular immune response in the parasitoid's host. Science. 211:582-583.

Feddersen I, Sander K, Schmidt O. 1986. Virus-like particles with host protein-like antigenic determinants protect an insect parasitoid from encapsulation. Experientia. 42:1278-1281.

Feschotte C, Gilbert C. 2012. Endogenous viruses: insights into viral evolution and impact on host biology. Nat. Rev. Genet. 13:283-296. doi: 10.1038/nrg3199.

3 Forbes AA, Bagley RK, Beer MA, Hippee AC, Widmayer HA. 2018. Quantifying the unquantifiable: why Hymenoptera, not Coleoptera, is the most speciose animal order. BMC Ecol. 18:21. 
785 Geib SM, Liang GH, Murphy TD, Sim SB. 2017. Whole genome sequencing of the braconid parasitoid 786 wasp Fopius arisanus, an important biocontrol agent of pest tephritid fruit flies. G3 . 7:2407-2411.

787 Goic B, Saleh M-C. 2012. Living with the enemy: viral persistent infections from a friendly viewpoint. 788 Curr. Opin. Microbiol. 15:531-537.

789 Gurevich A, Saveliev V, Vyahhi N, Tesler G. 2013. QUAST: quality assessment tool for genome 790 assemblies. Bioinformatics. 29:1072-1075.

791 Hamm JJ, Styer EL, Lewis WJ. 1990. Comparative virogenesis of filamentous virus and polydnavirus in 792 the female reproductive tract of Cotesia marginiventris (Hymenoptera: Braconidae). J. Invertebr. Pathol.

793 55:357-374. doi: 10.1016/0022-2011(90)90079-1.

794 Heavner ME et al. 2017. Novel organelles with elements of bacterial and eukaryotic secretion systems 795 weaponize parasites of Drosophila. Curr. Biol. 27:2869-2877.e6.

796 Holt C, Yandell M. 2011. MAKER2: an annotation pipeline and genome-database management tool for 797 second-generation genome projects. BMC Bioinformatics. 12:491.

798 Iyer LM, Aravind L, Koonin EV. 2001. Common origin of four diverse families of large eukaryotic DNA 799 viruses. J. Virol. 75:11720-11734.

800 Iyer LM, Balaji S, Koonin EV, Aravind L. 2006. Evolutionary genomics of nucleo-cytoplasmic large 801 DNA viruses. Virus Res. 117:156-184.

802 Iyer LM, Koonin EV, Aravind L. 2003. Evolutionary connection between the catalytic subunits of 803 DNA-dependent RNA polymerases and eukaryotic RNA-dependent RNA polymerases and the origin of 804 RNA polymerases. BMC Struct. Biol. 3:1.

805 Iyer LM, Leipe DD, Koonin EV, Aravind L. 2004. Evolutionary history and higher order classification of 806 AAA+ ATPases. J. Struct. Biol. 146:11-31.

807 Jones OR, Purvis A, Baumgart E, Quicke DLJ. 2009. Using taxonomic revision data to estimate the 808 geographic and taxonomic distribution of undescribed species richness in the Braconidae (Hymenoptera: 809 Ichneumonoidea). Insect Conserv. Diver. 2:204-212. doi: 10.1111/j.1752-4598.2009.00057.x.

810 Katoh K, Standley DM. 2013. MAFFT multiple sequence alignment software version 7: improvements in 811 performance and usability. Mol. Biol. Evol. 30:772-780.

812 Kawato $\mathrm{S}$ et al. 2018. Crustacean genome exploration feveals the evolutionary origin of White Spot 813 Syndrome Virus. J. Virol. 93. doi: 10.1128/jvi.01144-18.

814 Klopfstein $\mathrm{S}$ et al. 2019. Hybrid capture data unravel a rapid radiation of pimpliform parasitoid wasps 815 (Hymenoptera: Ichneumonidae: Pimpliformes). Syst. Entomol. 44:361-383.

816 Kool M, Ahrens CH, Goldbach RW, Rohrmann GF, Vlak JM. 1994. Identification of genes involved in

817 DNA replication of the Autographa californica baculovirus. Proc. Natl. Acad. Sci. U. S. A.

818 91:11212-11216. doi: 10.1073/pnas.91.23.11212.

819 Krell PJ. 1987. Replication of long virus-like particles in the reproductive tract of the ichneumonid wasp 
Diadegma terebrans. J. Gen. Virol. 68:1477-1483. doi: 10.1099/0022-1317-68-5-1477.

821 Kück P, Longo GC. 2014. FASconCAT-G: extensive functions for multiple sequence alignment preparations concerning phylogenetic studies. Front. Zool. 11. doi: 10.1186/s12983-014-0081-x.

823 Laetsch DR, Blaxter ML. 2017. BlobTools: Interrogation of genome assemblies. F1000Res. 6:1287.

824 Langmead B, Salzberg SL. 2013. Bowtie2. Nat. Methods. 9:357-359.

825 Lavialle C et al. 2013. Paleovirology of 'syncytins', retroviral env genes exapted for a role in

826 placentation. Philos. Trans. R Soc. Lond. B Biol. Sci. 368:20120507. doi: 10.1098/rstb.2012.0507.

827 Lawrence PO. 2005. Non-poly-DNA viruses, their parasitic wasps, and hosts. J. Insect Physiol.

828 51:99-101.

829 Lee MJ et al. 2009. Chapter 5 Virulence factors and strategies of Leptopilina spp.: Selective responses in 830 Drosophila hosts. Adv. Parasitol. 70:123-145. doi: 10.1016/s0065-308x(09)70005-3.

831 Lefkowitz EJ et al. 2018. Virus taxonomy: the database of the International Committee on Taxonomy of 832 Viruses (ICTV). Nucleic Acids Res. 46:D708-D717.

833 Leobold $\mathrm{M}$ et al. 2018. The domestication of a large DNA virus by the wasp Venturia canescens involves 834 targeted genome reduction through pseudogenization. Genome Biol. Evol. 10:1745-1764. doi:

$83510.1093 /$ gbe/evy127.

836 Lepetit D, Gillet B, Hughes S, Kraaijeveld K, Varaldi J. 2017. Genome sequencing of the behaviour 837 manipulating virus LbFV reveals a possible new virus family. Genome Biol. Evol. evw277. doi:

838 10.1093/gbe/evw277.

839 Li H et al. 2009. The Sequence Alignment/Map format and SAMtools. Bioinformatics. 25:2078-2079.

840 Louis F et al. 2013. The bracovirus genome of the parasitoid wasp Cotesia congregata is amplified within

84113 replication units, including sequences not packaged in the particles. J. Virol. 87:9649-9660. doi:

842 10.1128/jvi.00886-13.

843 Malmstrom CM, McCullough AJ, Johnson HA, Newton LA, Borer ET. 2005. Invasive annual grasses

844 indirectly increase virus incidence in California native perennial bunchgrasses. Oecologia. 145:153-164.

845 doi: 10.1007/s00442-005-0099-z.

846 Medd NC et al. 2018. The virome of Drosophila suzukii, an invasive pest of soft fruit. Virus Evolution. 4.

847 doi: 10.1093/ve/vey009.

848 Miller MA, Pfeiffer W, Schwartz T. 2010. Creating the CIPRES Science Gateway for inference of large

849 phylogenetic trees. 2010 Gateway Computing Environments Workshop (GCE). doi:

$85010.1109 /$ gce.2010.5676129.

851 Moran NA, Degnan PH, Santos SR, Dunbar HE, Ochman H. 2005. The players in a mutualistic

852 symbiosis: insects, bacteria, viruses, and virulence genes. Proc. Natl. Acad. Sci. U. S. A.

853 102:16919-16926.

854 Murphy N, Banks JC, Whitfield JB, Austin AD. 2008. Phylogeny of the parasitic microgastroid 
855 subfamilies (Hymenoptera: Braconidae) based on sequence data from seven genes, with an improved time 856 estimate of the origin of the lineage. Mol. Phylogenet. Evol. 47:378-395.

857 Parker BJ, Brisson JA. 2019. A laterally transferred viral gene modifies aphid wing plasticity. Current 858 Biol. 29:2098-2103.e5. doi: 10.1016/j.cub.2019.05.041.

859 Pichon A et al. 2015. Recurrent DNA virus domestication leading to different parasite virulence 860 strategies. Sci Adv. 1:e1501150.

861 Quicke DLJ, Laurenne NM, Fitton MG, Broad GR. 2009. A thousand and one wasps: a 28S rDNA and 862 morphological phylogeny of the Ichneumonidae (Insecta: Hymenoptera) with an investigation into 863 alignment parameter space and elision. J. Nat. Hist. 43:1305-1421.

864 Reineke A, Asgari S, Schmidt O. 2006. Evolutionary origin of Venturia canescens virus-like particles. 865 Arch. Insect Biochem. and Physiol. 61:123-133. doi: 10.1002/arch.20113.

866 Rice P, Longden I, Bleasby A. 2000. EMBOSS: the European Molecular Biology Open Software Suite. 867 Trends Genet. 16:276-277.

868 Rizki RM, Rizki TM. 1990. Parasitoid virus-like particles destroy Drosophila cellular immunity. Proc. 869 Natl. Acad. Sci. U. S. A. 87:8388-8392.

870 Rodriguez JJ et al. 2013. Extrapolations from field studies and known faunas converge on dramatically 871 increased estimates of global microgastrine parasitoid wasp species richness (Hymenoptera: Braconidae). 872 Insect Conserv. Divers. 6:530-536. doi: 10.1111/icad.12003.

873 Rohrmann GF. 2011. Baculovirus molecular biology. National Library of Medicine. National Center for 874 Biotechnology Information, Bethesda, MD. 188.

875 Roossinck MJ. 2011. The good viruses: viral mutualistic symbioses. Nat. Rev. Microbiol. 9:99-108.

876 Rossignol PA et al. 1985. Enhanced mosquito blood-finding success on parasitemic hosts: evidence for 877 vector-parasite mutualism. Proc. Natl. Acad. Sci. U. S. A. 82:7725-7727.

878 Rotheram S, Salt G. 1973. The surface of the egg of a parasitic insect. I. The surface of the egg and 879 first-instar larva of Nemeritis. Proc. Royal Soc. B. Biol. Sci. 183:179-194.

880 Ryabov EV, Keane G, Naish N, Evered C, Winstanley D. 2009. Densovirus induces winged morphs in 881 asexual clones of the rosy apple aphid, Dysaphis plantaginea. Proc. Natl. Acad. Sci. U. S. A.

882 106:8465-8470. doi: 10.1073/pnas.0901389106.

883 Salt G. 1965. Experimental studies in insect parasitism XIII. The haemocytic reaction of a caterpillar to 884 eggs of its habitual parasite. Proc. Royal Soc. B. Biol. Sci. 162:303-318.

885 Schmitt MJ, Breinig F. 2002. The viral killer system in yeast: from molecular biology to application. 886 FEMS Microbiol. Rev. 26:257-276.

887 Seemann T. 2014. Prokka: rapid prokaryotic genome annotation. Bioinformatics. 30:2068-2069.

888 Sharanowski BJ, Dowling APG, Sharkey MJ. 2011. Molecular phylogenetics of Braconidae

889 (Hymenoptera: Ichneumonoidea), based on multiple nuclear genes, and implications for classification. 
Syst. Entomol. 36:549-572.

891 Sharanowski BJ, Ridenbaugh R, Piekarski P, Broad GR, Burke GR, Deans AR, Lemmon AR, Lemmon

892 ER, Stewart G, Whitfield JB, Hines HM. 2020. Phylogenomics of Ichneumonoidea (Hymenoptera) and

893 implications for evolution of mode of parasitism and viral endogenization. bioRxiv.

894 Shen W, Xiong J. 2019. TaxonKit: a cross-platform and efficient NCBI taxonomy toolkit. bioRxiv.

895 513523. doi: 10.1101/513523.

896 Shi M et al. 2019. The genomes of two parasitic wasps that parasitize the diamondback moth. BMC

897 Genomics. 20:893.

898 Siddell SG et al. 2020. Binomial nomenclature for virus species: a consultation. Arch. Virol.

899 165:519-525. doi: 10.1007/s00705-019-04477-6.

900 Simão FA, Waterhouse RM, Ioannidis P, Kriventseva EV, Zdobnov EM. 2015. BUSCO: assessing

901 genome assembly and annotation completeness with single-copy orthologs. Bioinformatics.

902 31:3210-3212.

903 Stamatakis A. 2014. RAxML version 8: a tool for phylogenetic analysis and post-analysis of large

904 phylogenies. Bioinformatics. 30:1312-1313.

905 Stasiak K, Renault S, Federici BA, Bigot Y. 2005. Characteristics of pathogenic and mutualistic

906 relationships of ascoviruses in field populations of parasitoid wasps. J. Insect Physiol. 51:103-115. doi:

907 10.1016/j.jinsphys.2004.07.004.

908 Stoltz DB, Krell P, Summers MD, Vinson B. 1984. Polydnaviridae - A proposed family of insect viruses 909 with segmented, double-Stranded, circular DNA genomes. Intervirology. 21:1-4. doi:

$91010.1159 / 000149497$.

911 Stoltz DB, Whitfield JB. 1992. Viruses and virus-like entities in the parasitic Hymenoptera. J. Hymenopt. 912 Res. 1:125-139.

913 Strand MR. 2012. Polydnavirus gene products that interact with the host immune system. Parasitoid

914 Viruses. 149-161. doi: 10.1016/b978-0-12-384858-1.00012-6.

915 Strand MR, Burke GR. 2020. Polydnaviruses: Evolution and Function. Curr. Issues Mol. Biol.

916 34:163-182.

917 Strand MR, Burke GR. 2014. Polydnaviruses: Nature's genetic engineers. Annu. Rev. Virol. 1:333-354.

918 Strand MR, Drezen JM. 2012. Family Polydnaviridae. Virus taxonomy: ninth report of the international 919 committee on taxonomy of viruses. Amsterdam: Elsevier. 237-248.

920 Styer EL, Hamm JJ, Nordlund DA. 1987. A new virus associated with the parasitoid Cotesia

921 marginiventris (Hymenoptera: Braconidae): Replication in noctuid host larvae. J. Invert. Pathol.

922 50:302-309. doi: 10.1016/0022-2011(87)90096-6.

923 Suzuki M, Tanaka T. 2006. Virus-like particles in venom of Meteorus pulchricornis induce host hemocyte 924 apoptosis. J. Insect Physiol. 52:602-613. 
925 Townes H. 1965. Nomenclatural notes on European Ichneumonidae (Hymenoptera). Pol. Pismo Entomol. 926 35:409-417.

927 Tvedte ES et al. 2019. Genome of the parasitoid wasp Diachasma alloeum, an emerging model for 928 ecological speciation and transitions to asexual reproduction. Genome Biol. Evol. 11:2767-2773.

929 Varaldi J et al. 2006. Artifical transfer and morphological description of virus particles associated with 930 superparasitism behaviour in a parasitoid wasp. J. Insect Physiol. 52:1202-1212. doi:

931 10.1016/j.jinsphys.2006.09.002.

932 Villarreal LP. 2015. Force for ancient and recent life: viral and stem-loop RNA consortia promote life.

933 Ann. N. Y. Acad. Sci. 1341:25-34. doi: 10.1111/nyas.12565.

934 Villarreal LP, Witzany G. 2010. Viruses are essential agents within the roots and stem of the tree of life. J. 935 Theor. Biol. 262:698-710.

936 Volkoff A-N et al. 2010. Analysis of virion structural components reveals vestiges of the ancestral 937 ichnovirus genome. PLoS Pathog. 6:e1000923.

938 Wang Y, Bininda-Emonds ORP, Jehle JA. 2012. Nudivirus genomics and phylogeny. In: Viral Genomes 939 Molecular Structure, Diversity, Gene Expression Mechanisms and Host-Virus Interactions. Garcia, ML \& 940 Romanowski, V, editors. IntechOpen: Rijeka. doi: 10.5772/27793.

941 Whitfield JB, Asgari S. 2003. Virus or not? Phylogenetics of polydnaviruses and their wasp carriers. J.

942 Insect Physiol. 49:397-405.

943 Wu TD, Watanabe CK. 2005. GMAP: a genomic mapping and alignment program for mRNA and EST 944 sequences. Bioinformatics. 21:1859-1875.

945 Yin C et al. 2018. The genomic features of parasitism, polyembryony and immune evasion in the 946 endoparasitic wasp Macrocentrus cingulum. BMC Genomics. 19:420.

947 Yu DYE, Van Achterberg C, Horstmann K, Yu D, van Achterberg C. 2012. World Ichneumonoidea 2011.

948 Taxonomy, biology, morphology and distribution.

949 https://www.scienceopen.com/document?vid=55b95bf4-66fd-4cea-8b9b-27b4dbefc056.

950 Yutin N, Wolf YI, Raoult D, Koonin EV. 2009. Eukaryotic large nucleo-cytoplasmic DNA viruses:

951 clusters of orthologous genes and reconstruction of viral genome evolution. Virol. J. 6:223.

952 Zhang Y, Wang J, Han G-Z. 2020. Chalcid wasp paleoviruses bridge the evolutionary gap between

953 bracoviruses and nudiviruses. Virology. 542:34-39. 
bioRxiv preprint doi: https://doi.org/10.1101/2020.06.17.148684; this version posted June 18,2020 . The copyright holder for this preprint (which was not certified by peer review) is the author/funder. All rights reserved. No reuse allowed without permission.

954 Table 1. Taxa used for genome analysis. Higher Group placement is taken from Sharanowski et al. (2011) 955 and Sharanowski et al. (2020). Taxa not identified to species due to difficulty in accurate identification are 956 listed as sp.

\begin{tabular}{|c|c|c|c|c|c|}
\hline Assembly accession & Family & Higher Group & Subfamily & Genus species & $\begin{array}{l}\text { Expected or known } \\
\text { viral association }\end{array}$ \\
\hline & Braconidae & Microgastroid & Cheloninae & Phanerotoma sp. & Bracovirus \\
\hline & Braconidae & Euphoroid & Euphorinae & Meterous sp. & Unknown \\
\hline & Braconidae & Helconoid & Helconinae & $\begin{array}{l}\text { Eumacrocentrus } \\
\text { americanus }\end{array}$ & Unknown \\
\hline & Braconidae & Cyclostomes s.s. & Rogadinae & Aleiodes sp. & Unknown \\
\hline & Ichneumonidae & Ichneumoniformes & Adelognathinae & Adelognathus sp. & Unknown \\
\hline & Ichneumonidae & Ophioniformes & Banchinae & Lissonota sp. & Ichnovirus \\
\hline & Ichneumonidae & Ophioniformes & Campopleginae & Dusona sp. & Ichnovirus \\
\hline & Ichneumonidae & Ophioniformes & Ctenopelmatinae & Anoncus sp. & Unknown \\
\hline & Ichneumonidae & Ophioniformes & Mesochorinae & Mesochorus sp. & Unknown \\
\hline & Ichneumonidae & Pimpliformes & Pimplinae & Dolichomitus sp. & Unknown \\
\hline & Ichneumonidae & Xoridiformes & Xoridinae & Odontocolon sp. & Unknown \\
\hline \multicolumn{6}{|l|}{$\begin{array}{l}\text { Previously published } \\
\text { accessions }\end{array}$} \\
\hline GCA_000956155.1 & Braconidae & Microgastroid & Microgastrinae & Cotesia vestalis & Bracovirus \\
\hline GCA_001412515.3 & Braconidae & Alysioid & Opiinae & Diachasma alloeum & None discovered \\
\hline GCA_000806365.1 & Braconidae & Alysioid & Opiinae & Fopius arisanus & $\begin{array}{l}\text { Endogenous } \\
\text { nudivirus }\end{array}$ \\
\hline GCA_002156465.1 & Braconidae & Macrocentroid & Macrocentrinae & $\begin{array}{l}\text { Macrocentrus } \\
\text { cingulum }\end{array}$ & None discovered \\
\hline GCA_000572035.2 & Braconidae & Microgastroid & Microgastrinae & $\begin{array}{l}\text { Microplitis } \\
\text { demolitor }\end{array}$ & Bracovirus \\
\hline $\mathrm{N} / \mathrm{A}^{*}$ & Ichneumonidae & Ophioniformes & Campopleginae & Venturia canescens & $\begin{array}{l}\text { Endogenous } \\
\text { nudivirus }\end{array}$ \\
\hline
\end{tabular}

957

$958 *$ Genome available at: http://bipaa.genouest.org/sp/venturia_canescens 
959 Table 2. Matches to ancient core genes identified in sequenced wasp genomes.

\begin{tabular}{|c|c|c|c|c|c|c|c|c|c|c|c|c|}
\hline \multirow[t]{2}{*}{ Species } & \multicolumn{2}{|c|}{\begin{tabular}{|l|} 
DNA \\
polymerase \\
B
\end{tabular}} & \multicolumn{2}{|c|}{$\begin{array}{l}\text { Helicase / } \\
\text { Helicase III } \\
\text { (D5R-like } \\
\text { helicase) } \\
\end{array}$} & \multicolumn{2}{|c|}{$\begin{array}{l}\text { Lef-8 / } \\
\text { Rbp2 }\end{array}$} & \multicolumn{2}{|c|}{$\begin{array}{l}\text { Lef-9/ } \\
\text { Rbp1 }\end{array}$} & \multicolumn{2}{|c|}{$\begin{array}{l}\text { Lef-5 / } \\
\text { TFIIS-like } \\
\text { transcription } \\
\text { factor }\end{array}$} & \multicolumn{2}{|c|}{$\begin{array}{l}\text { P33 / } \\
\text { Sulfhydryl } \\
\text { oxidase }\end{array}$} \\
\hline & PSI & HMM & PSI & HMM & PSI & HMM & PSI & HMM & PSI & HMM & PSI & $\mathrm{HMM}$ \\
\hline Adelognathus sp. & 0 & 0 & 0 & 0 & 0 & 0 & 0 & 0 & 0 & 0 & 0 & 0 \\
\hline Aleiodes sp. & 0 & 0 & 0 & 0 & 0 & 0 & 0 & 0 & 0 & 0 & 0 & 0 \\
\hline Anoncus sp. & 0 & 0 & 0 & 0 & 0 & 0 & 0 & 0 & 0 & 0 & 0 & 0 \\
\hline Dolichomitus sp. & 1 & 1 & 1 & 0 & 2 & 2 & 1 & 0 & 0 & 0 & 0 & 0 \\
\hline Dusona sp. & 0 & 0 & 0 & 0 & 0 & 1 & 1 & 1 & 0 & 0 & 0 & 0 \\
\hline $\begin{array}{l}\text { Eumacrocentrus } \\
\text { americanus }\end{array}$ & 0 & 0 & 0 & 0 & 0 & 0 & 0 & 0 & 0 & 0 & 0 & 0 \\
\hline Lissonota sp. & 0 & 0 & 0 & 0 & 0 & 0 & 0 & 0 & 0 & 0 & 0 & 0 \\
\hline Mesochorus sp. & 0 & 0 & 0 & 0 & 0 & 0 & 0 & 0 & 0 & 0 & 0 & 0 \\
\hline Meterous sp. & 0 & 0 & 0 & 0 & 0 & 0 & 0 & 0 & 0 & 0 & 0 & 0 \\
\hline Odontocolon sp. & 0 & 0 & 0 & 0 & 0 & 0 & 0 & 0 & 0 & 0 & 0 & 0 \\
\hline Phanerotoma sp. & 0 & 0 & 0 & 0 & $2+$ & 2 & 1 & 1 & 0 & 0 & 1 & 1 \\
\hline Cotesia vestalis & 2 & 1 & 1 & 1 & 2 & 1 & 2 & 1 & 0 & 0 & 0 & 0 \\
\hline $\begin{array}{l}\text { Diachasma } \\
\text { alloeum }\end{array}$ & 0 & 0 & 0 & 0 & 0 & 0 & 0 & 0 & 0 & 0 & 0 & 0 \\
\hline Fopius arisanus & 0 & 0 & 1 & 1 & 1 & 1 & 1 & $2 *$ & 1 & 1 & 1 & 1 \\
\hline $\begin{array}{l}\text { Macrocentrus } \\
\text { cingulum }\end{array}$ & 0 & 0 & 0 & 0 & 0 & 0 & 0 & 0 & 0 & 0 & 0 & 0 \\
\hline $\begin{array}{l}\text { Microplitis } \\
\text { demolitor }\end{array}$ & 0 & 0 & 1 & 1 & 1 & 1 & 1 & 1 & 0 & 0 & 1 & 1 \\
\hline $\begin{array}{l}\text { Venturia } \\
\text { canescens }\end{array}$ & 0 & 0 & 1 & 1 & 1 & 1 & 1 & $2 *$ & 0 & 0 & 1 & 1 \\
\hline
\end{tabular}

$960 *$ ORFs with hits are located next to each other on scaffolds and are fragmented due to pseudogenization 961 or intron presence

962 +Likely one gene fragmented across two contigs 


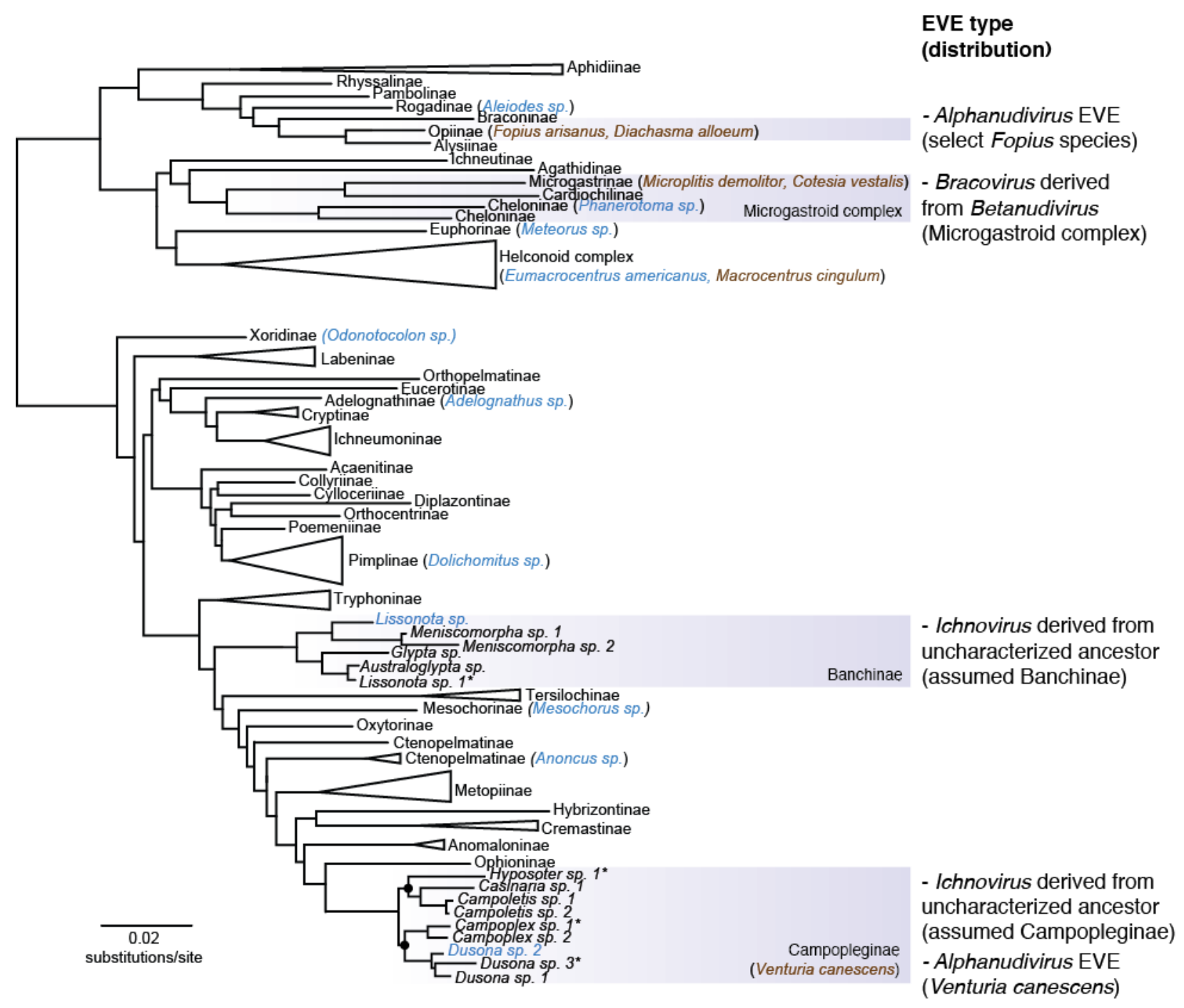

964 Figure 1. Maximum likelihood tree of Ichneumonoidea from Sharanowski et al. (2020). Subfamilies with multiple representatives (except the microgastroid complex, Campopleginae, and Banchinae) have been collapsed for viewing subfamily relationships, the presence and distribution of EVEs, and representative species analyzed in this study. Subfamilies with previously published, genetically characterized EVEs are shaded in boxes, and to the right, independent origins of EVEs, the type of virus ancestor they are derived from, and their known or assumed distribution is indicated. Two nodes within the Campopleginae are highlighted showing that the subfamily is divided into two major clades. Species analyzed in this study are placed next to the subfamily to which they belong and are colored blue (new genome assemblies) and brown (previously published genome assemblies). Taxa marked with an asterisk after the name have uncertain species identification. Support for the tree is robust and can be viewed in detail in Sharanowski

974 et al. (2020). 
bioRxiv preprint doi: https://doi.org/10.1101/2020.06.17.148684; this version posted June 18, 2020. The copyright holder for this preprint (which was not certified by peer review) is the author/funder. All rights reserved. No reuse allowed without permission.

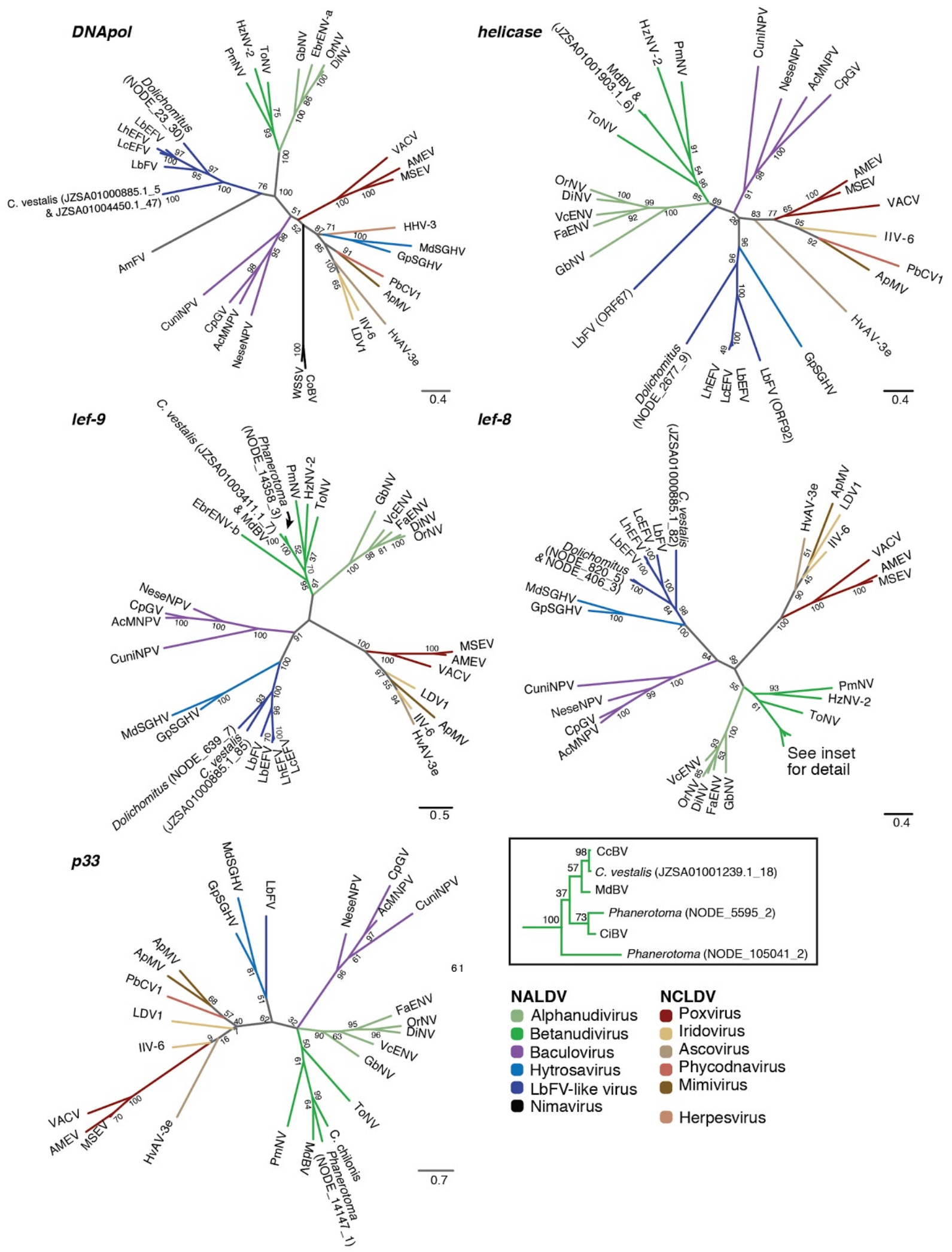


982 Figure 2. Genes of viral origin in wasp genomes are related to genes in large double-stranded

983 DNA viruses. Maximum likelihood phylogenies constructed from protein sequences of

984 individual genes are shown, with numbers on nodes indicating support from 100 bootstrap

985 replicates. Colored branches indicate virus families or groups. The sequences used for alignment

986 were obtained from Microplitis demoltior bracovirus (MdBV), Cotesia congregata bracovirus

987 (CcBV), Chelonus insularis bracovirus (CiBV), a C. chilonis transcriptome, Eurytoma

988 brunniventris endogenous nudivirus alpha (EbENV-a), Eurytoma brunniventris endogenous

989 nudivirus beta (EbENV-b), Tipula oleracea nudivirus (ToNV), Heliothis zea nudivirus 2

990 (HzNV-2), Penaeus monodon nudivirus (PmNV), Venturia canescens endogenous nudivirus

991 (VcENV), Drosophila innubila nudivirus (DiNV), Oryctes rhinoceros nudivirus (OrNV), Fopius

992 arisanus endogenous nudivirus (FaENV), Gryllus bimaculatus nudivirus (GbNV), Autographa

993 californica multiple nucleopolyhedrovirus (AcMNPV), Cydia pomonella granulovirus (CpGV),

994 Neodiprion sertifer nucleopolyhedrovirus (NeseMNPV), Culex nigripalpus nucleopolyhedrosis

995 virus (CuniNPV), Glossina pallidipes salivary gland hytrosavirus (GpSGHV), and Musca

996 domestica salivary gland hytrosavirus (MdSGHV), Leptopilina boulardi filamentous virus

997 (LbFV), Leptopilina boulardi endogenous filamentous virus (LbEFV), Leptopilina heterotoma

998 endogenous filamentous virus (LhEFV), Leptopilina clavipes endogenous filamentous virus

999 (LcEFV), Apis mellifera filamentous virus (AmFV), White spot syndrome virus (WSSV),

1000 Chionoecetes opilio bacilliform virus (CoBV), Amsacta moorei entomopoxvirus (AMEV),

1001 Melanoplus sanguinipes entomopoxvirus (MSEV), Vaccinia virus (VACV), Invertebrate

1002 iridescent virus 6 (IIV-6), LDV1, Trichoplusia ni ascovirus 3e (TnAV-3e), Paramecium bursaria

1003 chlorella virus 1 (PbCV1), Acanthamoeba polyphaga mimivirus (ApMV), Human herpesvirus 3

1004 (HHV-3), Table S5. Sequences from the IVSPERs of the ichnovirus in G. fumiferanae and

1005 nimavirus $p 33$ homologs were not included because they were too divergent compared to the

1006 other included sequences. Scale bars indicate substitutions per amino acid residue. For ORFs

1007 found in wasp genomes, the accession number or scaffold name is followed by an underscore

1008 and the ORF number.

1009

1010

1011

1012

1013

1014

1015 


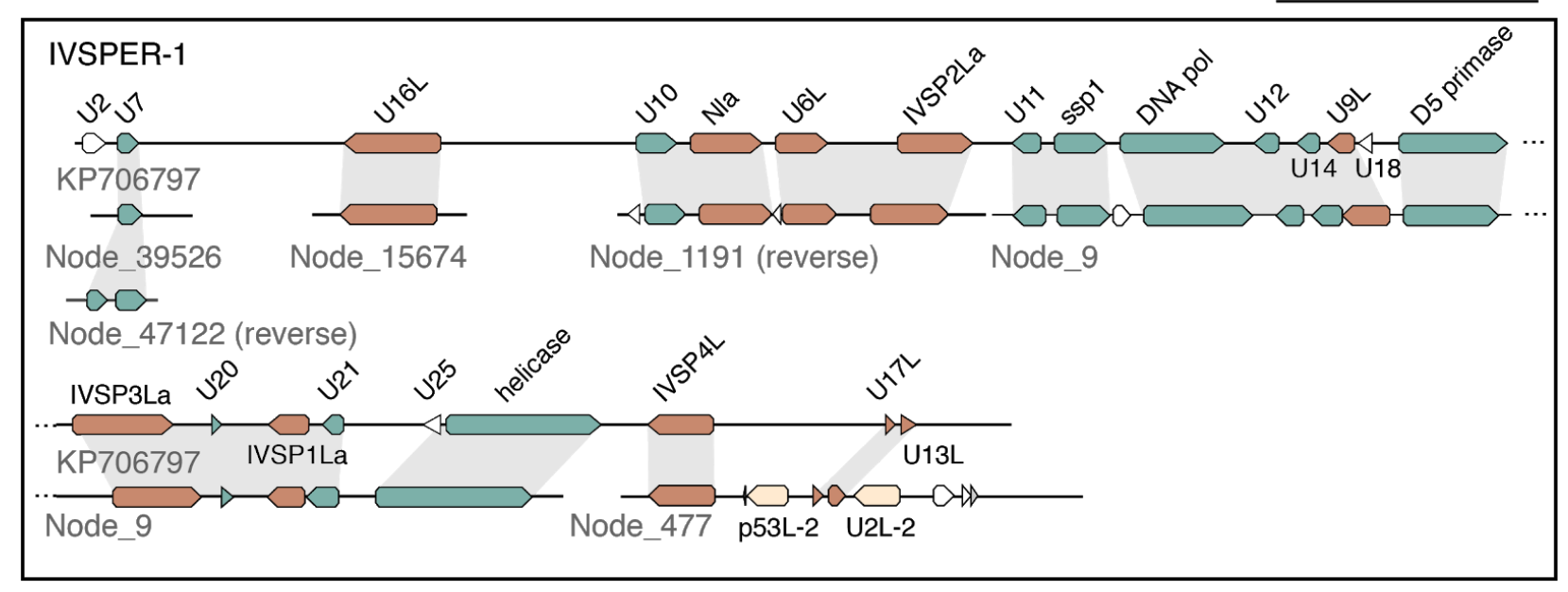

1016
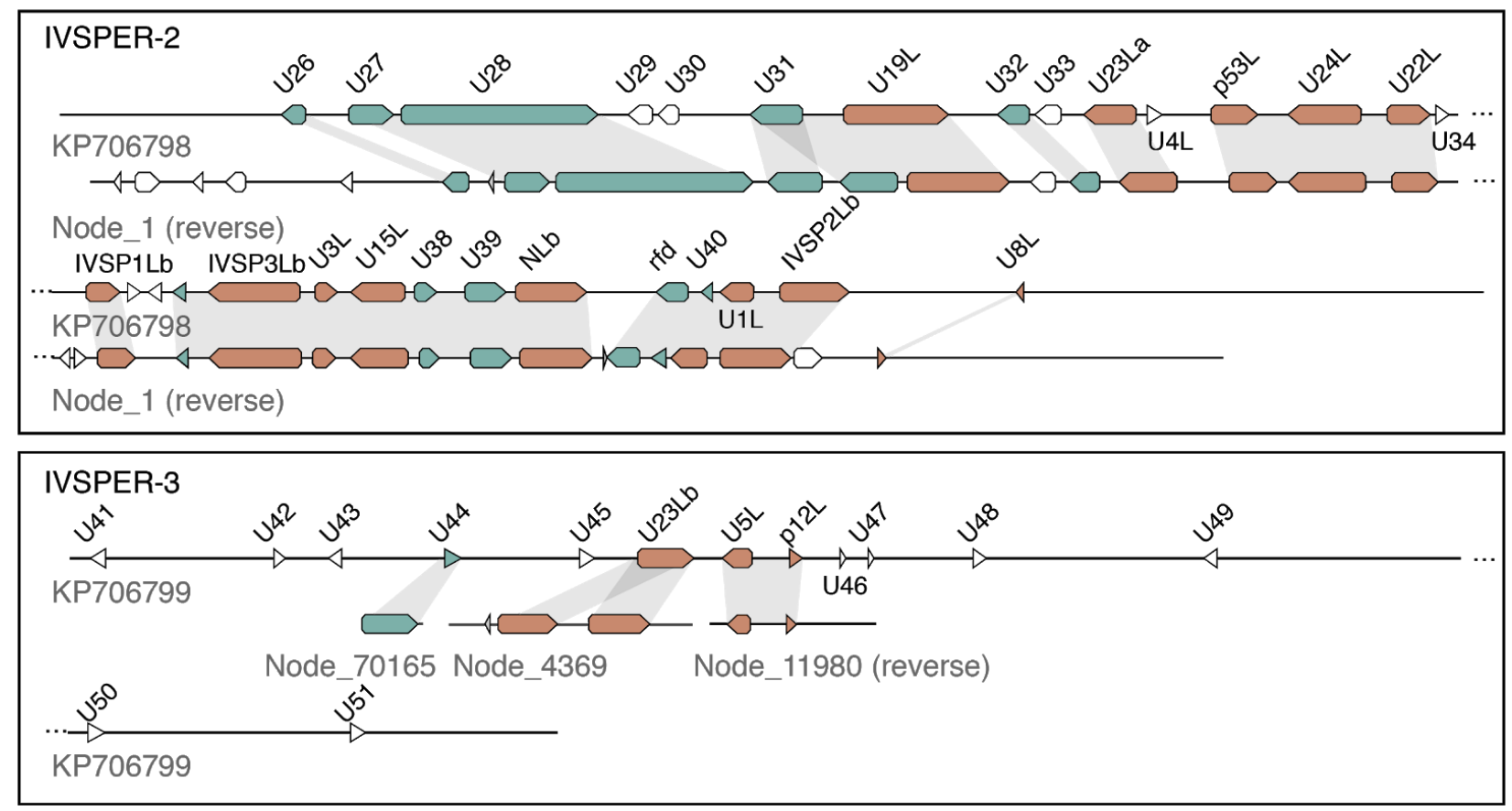

1017 Figure 3. IVSPER genes identified in the Lissonota genome and synteny with G. fumiferanae. G.

1018 fumiferanae sequences are shown above with Lissonota sequences shown below. Homologous genes with 1019 synteny between the two species are indicated by grey shading. Some genes are present in banchine and 1020 campoplegine species ( $G$. fumiferanae, Lissonota, and H. didymator; colored orange) while others are 1021 present only in the two banchine species presented here (blue). Genes colored beige are homologous to 1022 other IVSPER genes but are not detected in syntenous regions of the G. fumiferanae genome. 


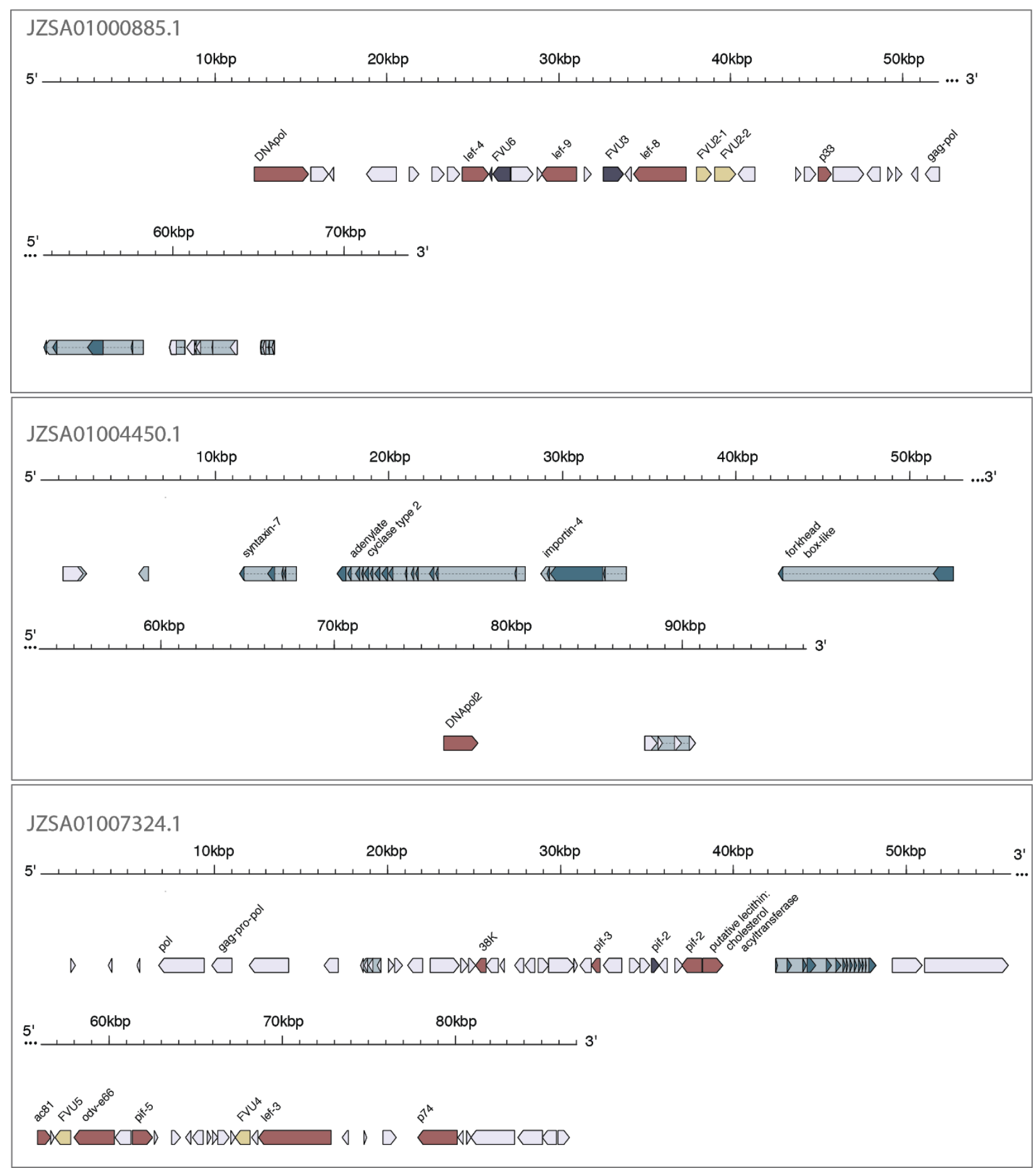

1026 Figure 4. Regions of the $C$. vestalis genome similar to the Leptopilina boulardi Filamentous Virus 1027 (LbFV). Genes with homology to LbFV are highlighted red, pseudogenes as a deep purple. Genes with 1028 homology to LbFV-like genes in Dolichomitus are shaded yellow or purple if pseudogenized (FVU = 1029 Filamentous Virus Unknown protein encoding gene). Other predicted genes are shaded in grey. Genes 1030 with blue background shading have eukaryotic structure (introns and exons), and of these, genes with 1031 dark blue colored exons are "high confidence" given evidence from EST alignments. 


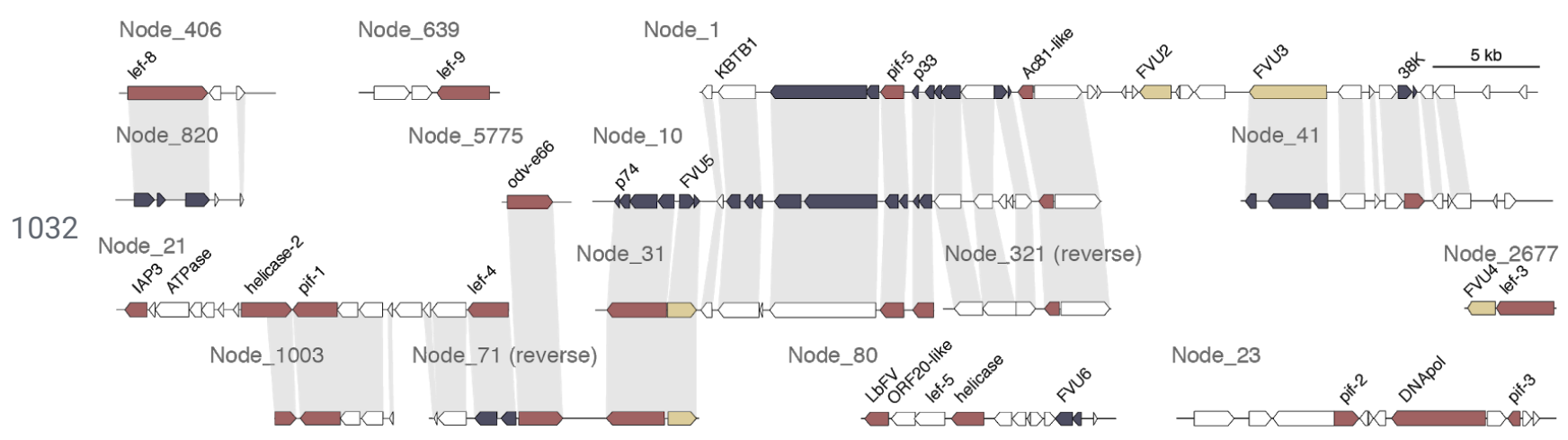

1033

1034 Figure 5. Regions of the Dolichomitus genome similar to the Leptopilina boulardi Filamentous Virus

1035 (LbFV). Homologous genes with synteny between contigs are indicated by grey shading. Genes with

1036 homology to LbFV are highlighted red, genes with homology to LbFV-like genes in C. vestalis are shaded

1037 yellow, and other predicted genes are colored white. FVU = Filamentous Virus Unknown protein

1038 encoding gene. ORFs shown in deep purple represent pieces of pseudogenes that can be found intact on

1039 other contigs. Three short nodes with incomplete gene sequences were not included in this figure

1040 (NODE_51377 and NODE_267127 containing pif-0, and NODE_236835 containing lef-9). 


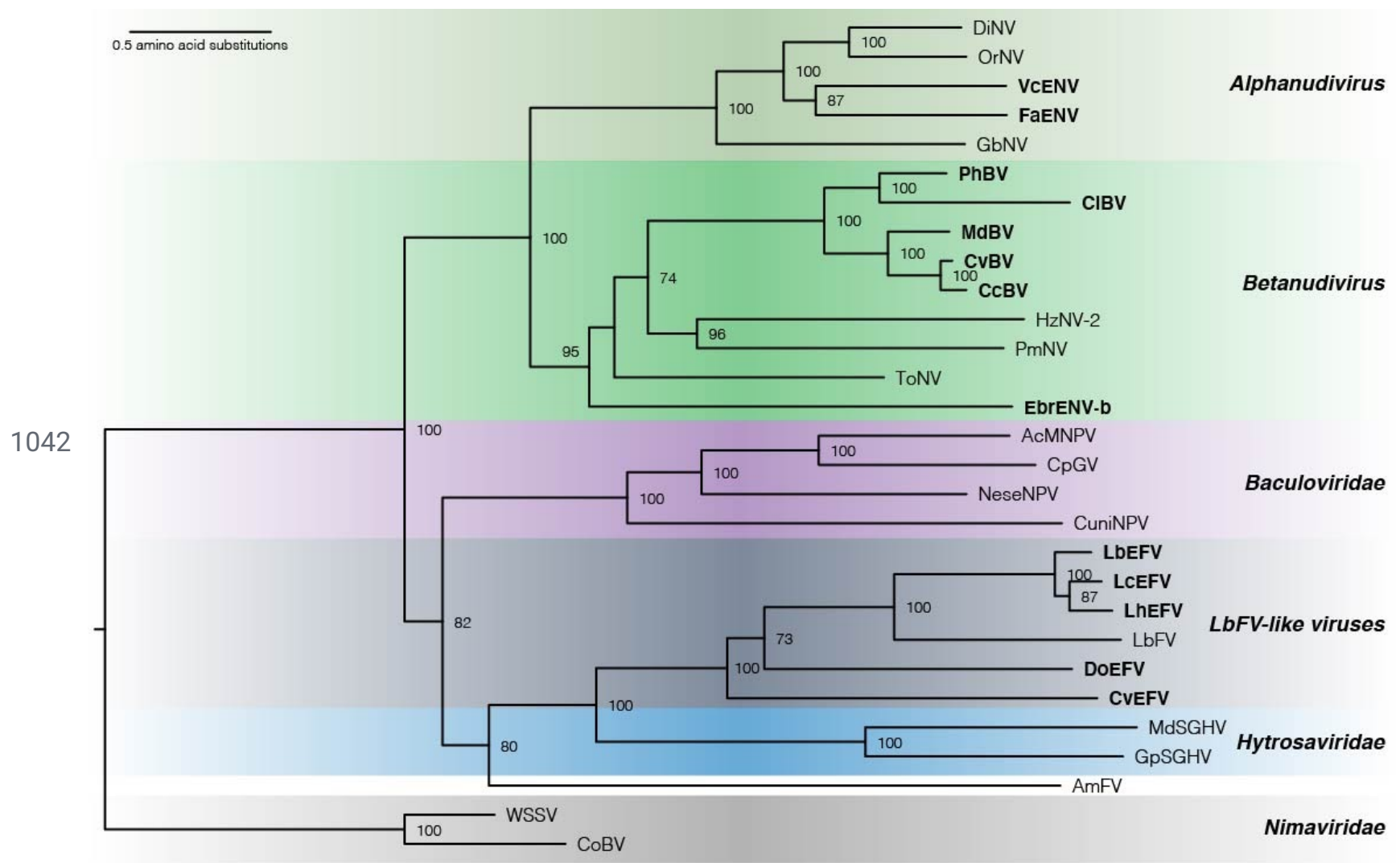

1043 Figure 6. Phylogenetic analysis of arthropod infecting large double-stranded DNA viruses and parasitoid

1044 EVEs. Relationships were derived using a maximum likelihood analysis from 12 core genes with a total

1045 of 5003 characters from concatenated amino acid sequences. Bootstrap values over $50 \%$ are indicated

1046 near the relevant node. Scale bar indicates average number of amino acid substitutions per site. Names of

1047 EVEs are highlighted with bold type. Taxa are named as in Figure 1, with the addition of Phanerotoma

1048 bracovirus (PhBV), Cotesia vestalis bracovirus (CvBV), Dolichomitus endogenous filamentous virus

1049 (DoEFV), and Cotesia vestalis endogenous filamentous virus (CvEFV). EbrENV-a was omitted because

1050 only one sequence (DNA polymerase) was available. 